\title{
Numerical Analysis of the Analytical Relationships between Angstrom Coefficients of Aerosols and Their Optical Properties for Four Types of Aerosols
}

\author{
Bello Idrith Tijjani ${ }^{1}$, Sha'aibu Uba ${ }^{2}$, Fatima Salman Koki ${ }^{1}$ \\ ${ }^{1}$ Department of Physics, Bayero University, Kano, Nigeria \\ ${ }^{2}$ Department of Physics, Ahmadu Bello University, Zaria, Nigeria \\ Email: idrith@yahoo.com, idrithtijjani@gmail.com, shuba356@yahoo.com, \\ shuba356@yahoo.com, FatimaSK2775@gmail.com
}

Received September 30, 2013; revised November 2, 2013; accepted November 10, 2013

Copyright (C) 2013 Bello Idrith Tijjani et al. This is an open access article distributed under the Creative Commons Attribution License, which permits unrestricted use, distribution, and reproduction in any medium, provided the original work is properly cited. In accordance of the Creative Commons Attribution License all Copyrights (C 2013 are reserved for SCIRP and the owner of the intellectual property Bello Idrith Tijjani et al. All Copyright (C) 2013 are guarded by law and by SCIRP as a guardian.

\begin{abstract}
In this paper, the authors numerically analyzed the analytical relationships between angstrom coefficients and optical properties of aerosols to the existing data extracted from OPAC at the spectral length of $0.25 \mu \mathrm{m}$ to $2.5 \mu \mathrm{m}$ at eight relative humidity for desert, urban, marine clean and continental clean aerosols. That is apart from their relationships with the wavelength that was determined, in this paper their relation with respect to aerosols' type and RHs are determined. The properties extracted are scattering, absorption, and extinction coefficients and single scattering albedo. The results showed that the extinction and single scattering albedo are correct for all the aerosols but single scattering co-albedo is satisfied for only sahara and continental clean.
\end{abstract}

Keywords: Angstrom Coefficients; Analytical Relationships; Parameterize; Wavelength Dependence; Optical Properties

\section{Introduction}

The Angstrom exponent (AC) is a parameter that is being widely used in atmospheric sciences to analyze the optical properties of aerosol particles. Since the early publications of Angstrom [1,2] and his later publications $[3,4]$, where this parameter was mainly applied to the description of the spectral behavior of the atmospheric extinction and transmission, respectively, it is now being applied to a variety of similar but slightly different optical properties, for instance to the atmospheric, optical depth, extinction coefficient, scattering or backscattering coefficients etc. It is very popular not only because of the simplicity of the equation, but because it enables extrapolation or interpolation of aerosols' optical properties, because it is connected to particle microphysics (related with the mean size of aerosols) as it describes, approximately for a certain radius range, and a spectral range, a power law (Junge) aerosol size distribution [5-8]. It was refined by O'Neill and Royer [9] who derived bimodal size distribution radii using these parameters.
The Angstrom exponent being an indicator of the aerosol spectral behaviour of aerosols [10], has been adopted by a number of authors in the literature to characterize biomass burning aerosols [11,12], urban and desert dust aerosol [13] and maritime aerosols [14]. In general, the aerosol optical depth (AOD) and AC parameters can be used to differentiate between coarse and fine particles [15].

Simple analytical relationships between extinction, scattering, and absorption coefficients and single scattering albedo (SSA) [16], and the corresponding relationships for $A C$ s [17] exist. Such relationships are useful to compare $A C$ s obtained from extinction, scattering, and absorption, including the ground truthing of remote sensing and satellite measurements. For example, aerosol extinction can be obtained from ground-based and satellite remote sensing at multiple wavelengths yielding extinction Angstrom coefficients (EACs). Simple analytical relationships between $E A C \mathrm{~s}$, scattering Angstrom coefficients $(S A C \mathrm{~s})$, and absorption Angstrom coefficients (AACs) 
will help attribute the $E A C$ s to the underlying physical phenomena, namely scattering and absorption, and analyzing closure between the different Angstrom coefficients. In addition, $S S A$ is the key parameter that normally determines the sign and magnitude of aerosol radiativeforcing. SSA can be obtained at multiple wavelengths from in-situ measurements $[7,8,18]$, ground-based remote sensing measurements $[19,20]$, and potentially from satellite measurements [21,22]. Relating the $S S A$ Angstrom coefficient ( $S S A A C$ ) to the underlying $S A C$, $A A C$, and $E A C$ will help with data interpretation and closure and physical understanding. The SSAs are some of the most dominant input factors that determine the aerosols type in radiative transfer models [23-26] and depend on the microphysical properties of the aerosols and therefore their value can be used for the characterization of the aerosol type. $S S A$ can be interpreted as the probability that light will be scattered, giving an extinction event or the ratio between the scattering coefficient and the extinction coefficient while the Single scattering co-albedo ( $S S C A$ ) can be considered as the probability of absorption per extinction event or ratio between the absorption coefficient and the extinction coefficient. Therefore if $S S A A C$ is less than 0 it indicates that $S S A$ increases with wavelength, while if $S S A A C$ is larger than $0, S S A$ decreases with wavelength. This shows that $S S A A C$ can be used to determine the increase or decrease in the radiative forcing and while for single scattering co-albedo Angstrom coefficient (SSCAAC) is the reverse. From the various plots we observed some spectral intervals where $S S A$ decreases with the wavelength as well as some spectral intervals where $S S A$ increases with the wavelength.

In addition, $A C$ s can be obtained from simple linear or nonlinear regression of data plotted on a log-log scale or more complicated non-linear fits of data that may also yield higher order terms which give additional information about the type of aerosols using the curvature [27]. Relationships between different $A C$ s that include the $S S A$ $(\omega)$ have only been derived by Moosmuller and Chakrabarty, [17] as for single- and two-wavelength $A C$ s, while for $A C$ s obtained from linear or non-linear fits the mathematics gets much more complicated due to the difficulty of appropriately attributing the influence of the $S S A$ at different wavelengths. However, in most cases, the single-wavelength equations still give a good approximation depending on the type of aerosols and relative humidity.

In aerosol optics, the $A C$ s that are of most interest are scattering, absorption, and extinction coefficients and for the $S S A(\omega)$ and single scattering co-albedo (SSCA). The relationships between these $A C$ s are analytically determined by Moosmuller and Chakrabarty, [17] as:

Extinction Angstrom coefficient $E A C$

$$
\operatorname{EAC}(\lambda)=A A C(\lambda)+\omega(\lambda)[S A C(\lambda)-A A C(\lambda)]
$$

Single Scattering Albedo ( $S S A)$ Angstrom coefficient (SSAAC)

$$
\operatorname{SSAAC}(\lambda)=\operatorname{SAC}(\lambda)-\operatorname{EAC}(\lambda)
$$

Single Scattering Co-Albedo (SSCA) Angstrom coefficient $(S S C A A C)$

$$
\operatorname{SSCAAC}(\lambda)=A A C(\lambda)-E A C(\lambda)
$$

As suggested by Moosmuller and Chakrabarty [17], in this paper we are going to apply these relationships to the existing data extracted from OPAC at the spectral length of $0.25 \mu \mathrm{m}$ to $2.5 \mu \mathrm{m}$ and eight RHs $(0 \%, 50 \%, 70 \%$, $80 \%, 90 \%, 95 \%, 98 \%$, and $99 \%$ ) for desert, urban, marine clean and continental clean to determine its accuracy and its dependence on the types of aerosols, the power of the polynomials and RHs (that is hygroscopic growth as a result of the change in RHs).

\section{Methodology}

The models extracted from OPAC are given in Table $\mathbf{1 .}$

The spectral behavior of the aerosol's optical parameter (X, say), with the wavelength of light $(\lambda)$ is expressed as inverse power law [3]:

Table 1. Compositions of aerosol types [28].

\begin{tabular}{ccc}
\hline Aerosol model types & Components & Concentration $N_{i}\left(\mathrm{~cm}^{-3}\right)$ \\
\hline \multirow{4}{*}{ Urban } & WASO & 28000.0 \\
& INSO & 1.5 \\
& SOOT & 130000.0 \\
& Total & 158001.5 \\
& WASO & 2600.0 \\
Continental clean & INSO & 0.15 \\
& Total & 26000.15 \\
& WASO & 2000.0 \\
Desert & MINM & 269.5 \\
& MIAM & 30.5 \\
& MICM & 0.142 \\
& Total & 2300.142 \\
& WASO & 1500.0 \\
Maritime clean & SSAM & 20.0 \\
& SSCM & 0.0032 \\
& Total & 1520.0032 \\
\hline
\end{tabular}

where: $N_{i}$ is the mass concentration of the component, water soluble components (WASO, consists of scattering aerosols, that are hygroscopic in nature, such as sulfates and nitrates present in anthropogenic pollution), water insoluble (INSO), soot (SOOT, not soluble in water and therefore the particles are assumed not to grow with increasing relative humidity), mineral nucleation mode (MINM), mineral accumulation mode(MIAM), mineral coarse mode (MICM), Sea salt accumulation mode (SSAM) and Sea salt coarse mode (SSCM). Urban aerosol represents strong pollution in urban areas. Continental clean aerosol represents remote continental areas without or with very low anthropogenic influences. Desert aerosol is used to describe aerosol over all deserts of the world, and no distinction with respect to the local properties is made. It consists of the mineral aerosol components in a combination that is representative for average turbidity, together with a certain part of the water-soluble component. Maritime aerosol types contain sea salt particles and Maritime clean is given to represent undisturbed remote maritime conditions with no soot, but with a certain amount of water-soluble aero-sol, which is used to represent the non-sea salt sulfate. 


$$
\mathrm{X}(\lambda)=\beta \lambda^{-\alpha}
$$

where $X(\lambda)$ can represent extinction, scattering, and absorption coefficients, single scattering albedo and single scattering co-albedo while $\beta$ is the turbidity and $\alpha$ is the Angstrom exponent $(A C)[9,29]$. The wavelength dependence of $\mathrm{X}(\lambda)$ can be characterized by the $A C$, which is a coefficient of the following regression:

$$
\ln X(\lambda)=-\alpha \ln (\lambda)+\ln \beta
$$

However the Angstrom exponent itself varies with wavelength, and a more precise empirical relationship between aerosol extinction and wavelength is obtained with a 2 nd-order polynomial [13,30-38] as:

$$
\ln \mathrm{X}(\lambda)=\alpha_{2}(\ln \lambda)^{2}+\alpha_{1} \ln \lambda+\ln \beta
$$

Here, the coefficient $\alpha_{2}$ accounts for a "curvature" often observed in sunphotometry measurements. Eck et al. [12,13], Schuster et al., [27], O' Neill et al., [34] and Kaskaoutis et al., [39,40] reported the existence of negative curvatures for fine-mode aerosols and near zero or positive curvatures are characteristic of size distributions with a dominant coarse-mode or bimodal distributions with coarse-mode aerosols having a significant relative magnitude.

Now differentiating Equation (5) with respect to $\ln \lambda$ we obtained

$$
\alpha=-\frac{\mathrm{d}(\ln \mathrm{X}(\lambda))}{\mathrm{d}(\ln (\lambda))}
$$

Also differentiating Equation (6) with respect to $\ln \lambda$ we obtained

$$
\frac{\mathrm{d}(\ln \mathrm{X}(\lambda))}{\mathrm{d}(\ln (\lambda))}=\alpha_{1}+2 \alpha_{2} \ln (\lambda)
$$

Assuming that Equations (7) and (8) are evaluated at a wavelength, this implies we can substitute Equation (7) into (8) to obtain

$$
\alpha 1(\lambda)=-\alpha_{1}-2 \alpha_{2} \ln (\lambda)
$$

Equation (9) now shows the relationship between $\alpha$ and wavelength.

We now also proposed a cubic relation of the form

$$
\ln \mathrm{X}(\lambda)=\ln \beta+\alpha_{1} \ln \lambda+\alpha_{2}(\ln \lambda)^{2}+\alpha_{3}(\ln \lambda)^{3}
$$

to determine whether cubic relation can improve the accuracy of Equations (1)-(3).

Also differentiating Equation (10) with respect to $\ln \lambda$ we obtained

$$
\frac{\mathrm{d}(\ln \mathrm{X}(\lambda))}{\mathrm{d}(\ln (\lambda))}=\alpha_{1}+2 \alpha_{2} \ln (\lambda)+3 \alpha_{3}(\ln (\lambda))^{2}
$$

Assuming that Equations (7) and (11) are evaluated at a wavelength, this implies we can substitute Equation (7) into (11) to obtain

$$
\alpha 2(\lambda)=-\alpha_{1}-2 \alpha_{2} \ln (\lambda)-3 \alpha_{3}(\ln (\lambda))^{2}
$$

In this paper we are going to determine the correlation of Equations (1)-(3) with Equations (7), (9) and (12) for all the four types of the aerosols with respect to wavelengths and RHs. In Equation (1) since it involves products, we determined the average, but in Equations (2) and (3), since they have linear relations, we compared the coefficients.

\section{Results and Observations}

Figure 1(a) shows that power law is satisfied at $90 \%$, $95 \%, 98 \%$ and $99 \% \mathrm{RH}$, but not satisfied at $0 \%, 50 \%$, $70 \%$, and $80 \%$.

Table 2(a) shows good correlations at 90\%, 95\%, 98\% and $99 \% \mathrm{RH}$, but bad correlations $0 \%, 50 \%, 70 \%$, and $80 \% \mathrm{RH}$ for linear. The increase in the power of the polynomials and RHs caused increase in the correlations.

Figure 1(b) shows that the plots can be approximated by the power law.

Table 2(b) shows very good correlations, and the correlations increase with the increase in the power of the polynomials and RHs.

Figure 1(c), spectral extinction coefficients decrease with wavelength and can be approximated with a powerlaw wavelength dependence and also a bi-modal type of particle size distributions [13]. The increase of the coefficients with RH has occurred because of the increase in mode size as a result of the increase in RHs. The increase of the extinction with $\mathrm{RH}$ at the deliquescence point $(90$ to 99 ) is that the growth increase substantially, making the process strongly nonlinear with RH [41,42].

Table 2(c) shows good correlations between extinction and $\lambda$ using Equations (5), (6) and (10). The correlations increase with the increase in the power of the polynomials and RHs.

Observing Figures 1(a) and Table 2(a), it can be seen that at RHs $0 \%$ to $90 \%$ the scattering coefficients have not satisfied the power law, and within this range it can be observed that in Table 2(d), Equation (1) underestimated Equation (7) on the linear part but overestimated Equations (9) and (12) on the quadratic and cubic part respectively at all the RHs. The gaps decrease with the increase in RHs.

Figure 1(d) shows that the plots can be barely approximated by the power law.

Table 2(e) shows that the correlations decrease with the increase in $\mathrm{RH}$, but increase with the increase in the power of the polynomials.

Comparing the coefficients at Tables 2(e) and (f) it 


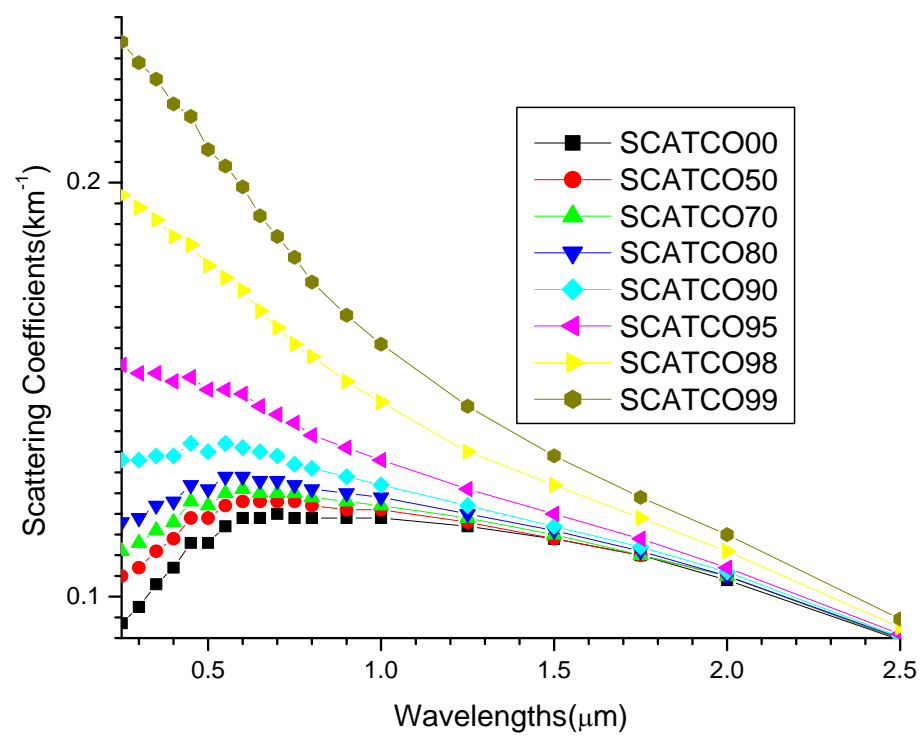

Figure 1(a). A graph of scattering coefficients against wavelength for sahara at RHs $\mathbf{0 \%}, \mathbf{5 0 \% , 7 0 \% , 8 0 \% , 9 0 \% , 9 5 \% , 9 8 \% ~}$ and $99 \%$.

Table 2(a). The results of the Angstrom coefficients of scattering coefficients using Equations (5), (6) and (10) for sahara model at the respective relative humidities using regression analysis with SPSS16.0.

\begin{tabular}{cccccccccc}
\hline $\mathrm{RH}$ & \multicolumn{2}{c}{ Linear Equation (5) } & \multicolumn{3}{c}{ Quadratic Equation (6) } & \multicolumn{4}{c}{ Cubic Equation (10) } \\
\hline$(\%)$ & $\mathrm{R}^{2}$ & $\alpha$ & $\mathrm{R}^{2}$ & $\alpha_{1}$ & $\alpha_{2}$ & $\mathrm{R}^{2}$ & $\alpha_{1}$ & $\alpha_{2}$ & $\alpha_{3}$ \\
\hline 0 & 0.0053 & -0.0101 & 0.9653 & -0.0819 & -0.2002 & 0.9829 & -0.0515 & -0.2349 & -0.0455 \\
50 & 0.0800 & 0.0355 & 0.9537 & -0.1153 & -0.1738 & 0.9805 & -0.0812 & -0.2127 & -0.0510 \\
70 & 0.2250 & 0.0606 & 0.9551 & -0.1349 & -0.1617 & 0.9817 & -0.1002 & -0.2012 & -0.0518 \\
80 & 0.3960 & 0.0853 & 0.9606 & -0.1547 & -0.1511 & 0.9839 & -0.1203 & -0.1903 & -0.0515 \\
90 & 0.6899 & 0.1389 & 0.9754 & -0.1997 & -0.1324 & 0.9890 & -0.1673 & -0.1694 & -0.0485 \\
95 & 0.8629 & 0.2082 & 0.9887 & -0.2624 & -0.1179 & 0.9937 & -0.2362 & -0.1478 & -0.0392 \\
98 & 0.9377 & 0.3124 & 0.9961 & -0.3655 & -0.1156 & 0.9967 & -0.3522 & -0.1307 & -0.0198 \\
99 & 0.9488 & 0.3841 & 0.9978 & -0.4435 & -0.1293 & 0.9978 & -0.4399 & -0.1335 & -0.0055 \\
\hline
\end{tabular}

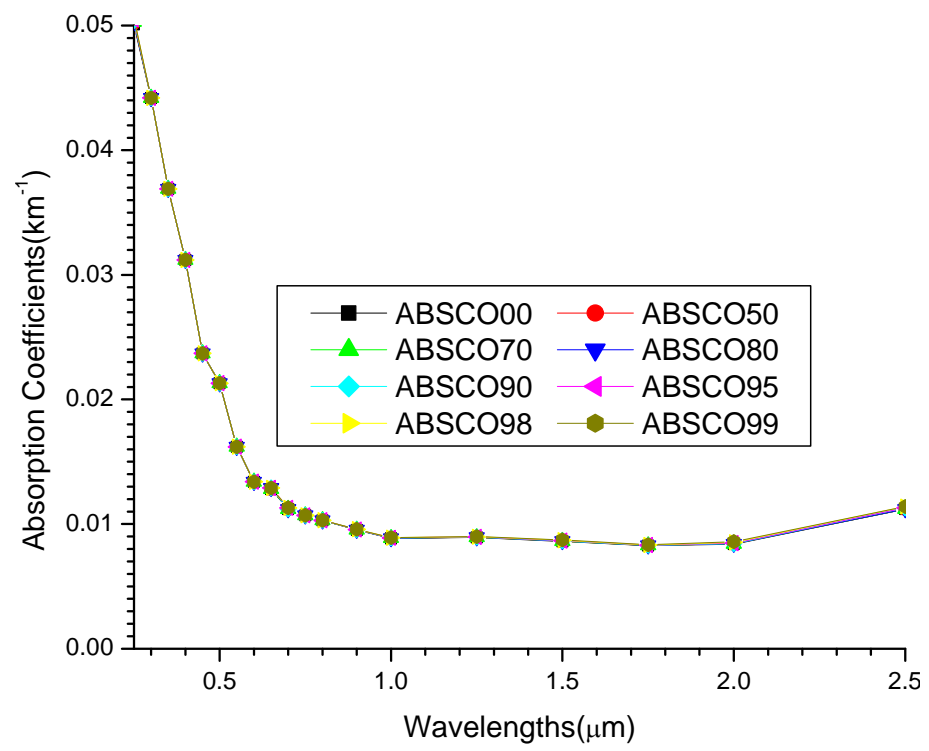

Figure 1(b). A graph of absorption coefficients against wavelength for sahara at RHs $0 \%, \mathbf{5 0} \%, \mathbf{7 0} \%, \mathbf{8 0} \%, \mathbf{9 0 \% , 9 5 \% , 9 8 \%}$ and $99 \%$. 
Table 2(b). The results of the Angstrom coefficients of absorption coefficients using Equations (5), (6) and (10) for sahara model at the respective relative humidities using regression analysis with SPSS16.0.

\begin{tabular}{ccccccccccc}
\hline $\mathrm{RH}$ & \multicolumn{2}{c}{ Linear Equation (5) } & \multicolumn{3}{c}{ Quadratic Equation (6) } & \multicolumn{5}{c}{ Cubic Equation (10) } \\
\hline$(\%)$ & $\mathrm{R}^{2}$ & $\alpha$ & $\mathrm{R}^{2}$ & $\alpha_{1}$ & $\alpha_{2}$ & $\mathrm{R}^{2}$ & $\alpha_{1}$ & $\alpha_{2}$ & $\alpha_{3}$ \\
\hline 0 & 0.7568 & 0.8058 & 0.9684 & -0.5157 & 0.6315 & 0.9821 & -0.6961 & 0.8374 & 0.2698 \\
50 & 0.7562 & 0.8050 & 0.9686 & -0.5144 & 0.6325 & 0.9821 & -0.6932 & 0.8365 & 0.2673 \\
70 & 0.7559 & 0.8047 & 0.9687 & -0.5139 & 0.6329 & 0.9821 & -0.6921 & 0.8362 & 0.2665 \\
80 & 0.7557 & 0.8043 & 0.9688 & -0.5134 & 0.6332 & 0.9822 & -0.6912 & 0.8360 & 0.2659 \\
90 & 0.7551 & 0.8036 & 0.9689 & -0.5124 & 0.6340 & 0.9822 & -0.6896 & 0.8361 & 0.2650 \\
95 & 0.7541 & 0.8025 & 0.9690 & -0.5108 & 0.6350 & 0.9822 & -0.6875 & 0.8366 & 0.2643 \\
98 & 0.7519 & 0.8003 & 0.9690 & -0.5074 & 0.6375 & 0.9823 & -0.6843 & 0.8392 & 0.2645 \\
99 & 0.7497 & 0.7979 & 0.9689 & -0.5040 & 0.6397 & 0.9824 & -0.6816 & 0.8422 & 0.2655 \\
\hline
\end{tabular}

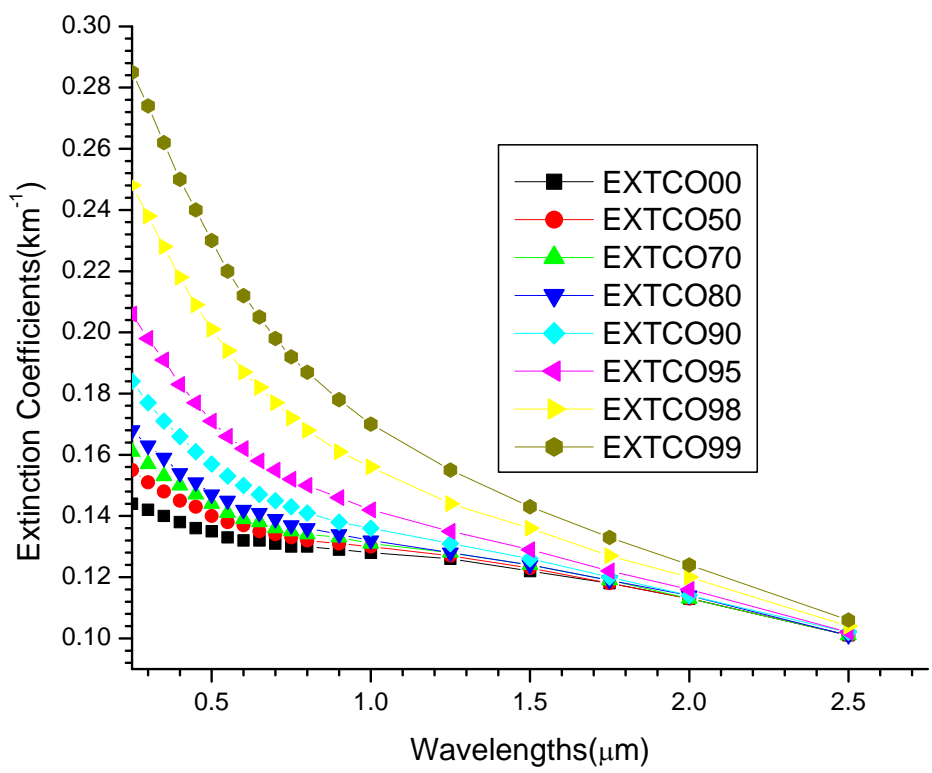

Figure 1(c). A graph of extinction coefficients against wavelength for sahara at RHs $\mathbf{0 \%}, \mathbf{5 0 \% , 7 0 \% , 8 0 \% , 9 0 \% , 9 5 \% , 9 8 \% ~}$ and $99 \%$.

Table 2(c). The results of the Angstrom coefficients of extinction coefficients using Equations (5), (6) and (10) for sahara model at the respective relative humidities using regression analysis with SPSS16.0.

\begin{tabular}{ccccccccccc}
\hline $\mathrm{RH}$ & \multicolumn{2}{c}{ Linear Equation (5) } & \multicolumn{3}{c}{ Quadratic Equation (6) } & \multicolumn{4}{c}{ Cubic Equation (10) } \\
\hline$(\%)$ & $\mathrm{R}^{2}$ & $\alpha$ & $\mathrm{R}^{2}$ & $\alpha_{1}$ & $\alpha_{2}$ & $\mathrm{R}^{2}$ & $\alpha_{1}$ & $\alpha_{2}$ & $\alpha_{3}$ \\
\hline 0 & 0.8824 & 0.1225 & 0.9422 & -0.1442 & -0.0473 & 0.9880 & -0.0979 & -0.1001 & -0.0693 \\
50 & 0.9411 & 0.1552 & 0.9624 & -0.1711 & -0.0346 & 0.9911 & -0.1261 & -0.0859 & -0.0673 \\
70 & 0.9583 & 0.1733 & 0.9706 & -0.1867 & -0.0291 & 0.9922 & -0.1435 & -0.0784 & -0.0646 \\
80 & 0.9697 & 0.1918 & 0.9770 & -0.2031 & -0.0247 & 0.9932 & -0.1620 & -0.0716 & -0.0615 \\
90 & 0.9836 & 0.2320 & 0.9864 & -0.2404 & -0.0182 & 0.9948 & -0.2047 & -0.0588 & -0.0533 \\
95 & 0.9916 & 0.2855 & 0.9932 & -0.2933 & -0.0169 & 0.9963 & -0.2670 & -0.0469 & -0.0393 \\
98 & 0.9942 & 0.3684 & 0.9974 & -0.3827 & -0.0310 & 0.9977 & -0.3722 & -0.0430 & -0.0156 \\
99 & 0.9914 & 0.4272 & 0.9985 & -0.4517 & -0.0535 & 0.9985 & -0.4520 & -0.0532 & 0.0004 \\
\hline
\end{tabular}


Table 2(d). The results of the Angstrom coefficients of extinction coefficients using Equations (1), (7), (9) and (12) for sahara model at the respective relative humidities using regression analysis with SPSS16.0.

\begin{tabular}{ccccccc}
\hline RH & \multicolumn{2}{c}{ Linear } & \multicolumn{2}{c}{ Quadratic } & \multicolumn{2}{c}{ Cubic } \\
\hline$(\%)$ & Equation (7) & Equation (1) & Equation (9) & Equation $(1)$ & Equation (12) & Equation $(1)$ \\
\hline & $A$ & $A$ & $\alpha_{1}(\lambda)$ & $\alpha_{1}(\lambda)$ & $\alpha_{2}(\lambda)$ & $\alpha_{2}(\lambda)$ \\
\hline 0 & 0.122451 & 0.101199 & 0.115492 & 0.159794 & 0.139420 & 0.141914 \\
50 & 0.155226 & 0.136194 & 0.150135 & 0.189424 & 0.173392 & 0.175070 \\
70 & 0.173292 & 0.155676 & 0.169010 & 0.206057 & 0.191334 & 0.192991 \\
80 & 0.191773 & 0.175054 & 0.188141 & 0.222690 & 0.209395 & 0.210576 \\
90 & 0.231990 & 0.217366 & 0.229310 & 0.259265 & 0.247712 & 0.248438 \\
95 & 0.285518 & 0.273175 & 0.283026 & 0.307763 & 0.296618 & 0.296840 \\
98 & 0.368436 & 0.359011 & 0.363871 & 0.382144 & 0.369275 & 0.368879 \\
99 & 0.427181 & 0.419607 & 0.419313 & 0.433753 & 0.419175 & 0.418214 \\
\hline
\end{tabular}

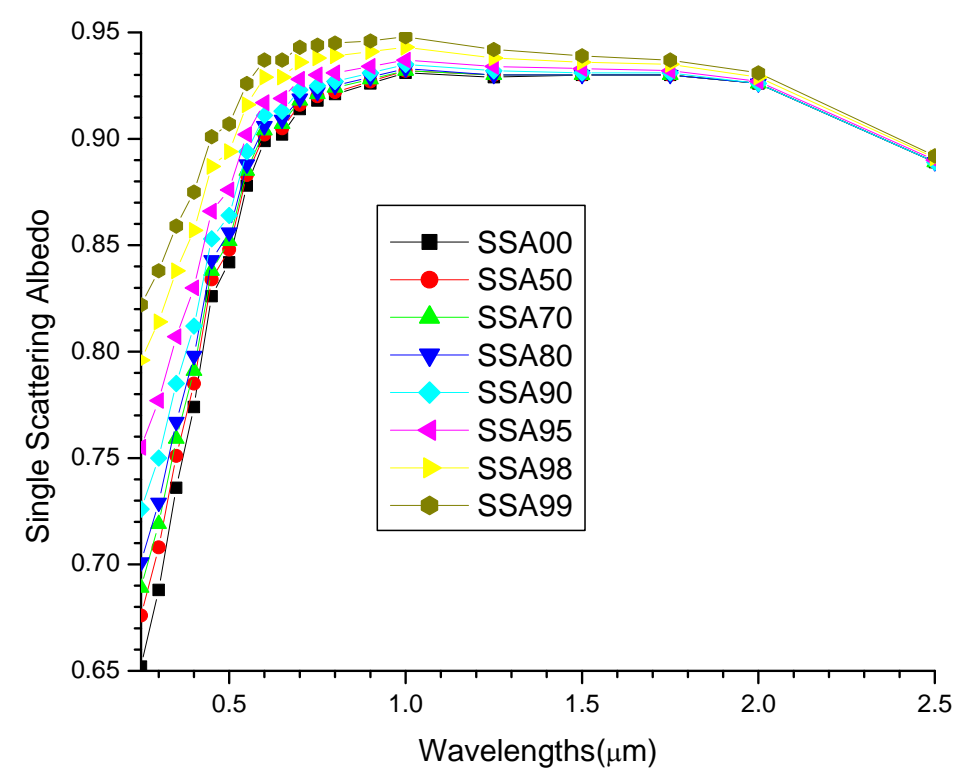

Figure 1(d). A graph of single scattering albedo against wavelength for sahara at RHs $0 \%, 50 \%, 70 \%, 80 \%, 90 \%, 95 \%, 98 \%$ and $99 \%$.

Table 2(e). The results of the Angstrom coefficients of single scattering albedo using Equations (5), (6) and (10) for sahara model at the respective relative humidities using regression analysis with SPSS16.0.

\begin{tabular}{ccccccccccc}
\hline $\mathrm{RH}$ & \multicolumn{2}{c}{ Linear Equation (5) } & \multicolumn{3}{c}{ Quadratic Equation (6) } & \multicolumn{5}{c}{ Cubic Equation (10) } \\
\hline$(\%)$ & $\mathrm{R}^{2}$ & $\alpha$ & $\mathrm{R}^{2}$ & $\alpha_{1}$ & $\alpha_{2}$ & $\mathrm{R}^{2}$ & $\alpha_{1}$ & $\alpha_{2}$ & $\alpha_{3}$ \\
\hline 0 & 0.6130 & -0.1325 & 0.9840 & 0.0623 & -0.1529 & 0.9873 & 0.0463 & -0.1346 & 0.0239 \\
50 & 0.6085 & -0.1197 & 0.9840 & 0.0556 & -0.1393 & 0.9859 & 0.0446 & -0.1268 & 0.0165 \\
70 & 0.6044 & -0.1129 & 0.9838 & 0.0520 & -0.1326 & 0.9851 & 0.0433 & -0.1226 & 0.0130 \\
80 & 0.5993 & -0.1064 & 0.9835 & 0.0484 & -0.1263 & 0.9844 & 0.0416 & -0.1186 & 0.0102 \\
90 & 0.5838 & -0.0931 & 0.9828 & 0.0407 & -0.1141 & 0.9830 & 0.0373 & -0.1103 & 0.0051 \\
95 & 0.5534 & -0.0773 & 0.9814 & 0.0310 & -0.1008 & 0.9814 & 0.0307 & -0.1005 & 0.0001 \\
98 & 0.4796 & -0.0561 & 0.9787 & 0.0171 & -0.0848 & 0.9791 & 0.0197 & -0.0878 & -0.0039 \\
99 & 0.4041 & -0.0430 & 0.9763 & 0.0082 & -0.0758 & 0.9775 & 0.0121 & -0.0803 & -0.0059 \\
\hline
\end{tabular}


Table 2(f). The results of the Angstrom coefficients of single scattering albedo using Equation (2) for sahara model at the respective relative humidities

\begin{tabular}{|c|c|c|c|c|c|c|}
\hline \multirow{2}{*}{$\begin{array}{l}\text { RH } \\
(\%)\end{array}$} & \multirow{2}{*}{$\begin{array}{c}\text { Linear } \\
A\end{array}$} & \multicolumn{2}{|c|}{ Quadratic } & \multicolumn{3}{|c|}{ Cubic } \\
\hline & & $\alpha_{1}$ & $\alpha_{2}$ & $\alpha_{1}$ & $\alpha_{2}$ & $\alpha_{3}$ \\
\hline 0 & -0.132502 & 0.062268 & -0.15288 & 0.046363 & -0.13473 & 0.023788 \\
\hline 50 & -0.119753 & 0.055814 & -0.13917 & 0.044891 & -0.12671 & 0.016337 \\
\hline 70 & -0.112727 & 0.051800 & -0.13262 & 0.043217 & -0.12283 & 0.012838 \\
\hline 80 & -0.106435 & 0.048374 & -0.12638 & 0.041661 & -0.11872 & 0.01004 \\
\hline 90 & -0.093124 & 0.040653 & -0.11421 & 0.037474 & -0.11059 & 0.004755 \\
\hline 95 & -0.077282 & 0.030909 & -0.10094 & 0.030828 & -0.10085 & 0.000121 \\
\hline 98 & -0.056080 & 0.017218 & -0.08459 & 0.019982 & -0.08774 & -0.00413 \\
\hline 99 & -0.043050 & 0.008194 & -0.07587 & 0.01212 & -0.08035 & -0.00587 \\
\hline
\end{tabular}

can be observed that they are approximately the same with some to three places of decimal while some to four places of decimals.

Figure 1(e) shows it is almost the opposite of Figure 1(d), and the plots can be barely approximated by power law and it decreases with the increase in $\mathrm{RH}$.

Table 2(g) shows that the correlations decrease with the increase in $\mathrm{RH}$, but increase with the increase in the power of the polynomials.

Comparing the coefficients in Tables 2(g) and (h) it can be observed that they are approximately the same, some to one place of decimals while some to two places of decimals.

Figure 2(a) shows a steep but smooth decrease of the extinction coefficients with wavelengths and all the plots satisfy power law.

Table 3(a) shows very good correlations for all the polynomials, and the correlations increase with the increase in the powers of the polynomials.

Figure 2(b) shows a steep but smooth curves that decrease with the increase in wavelength, but shows little effect with the increase in RH. They all satisfy power law.

Table 3(b) shows very good correlations for all the polynomials, and the correlations increase with the increase in the powers of the polynomials.

Figures 2(c) and (a) are almost similar.

Table 3(c) shows very good correlations for all the equations, but the correlation increases with the increase in the power of the polynomials.

From Table 3(d) it can be seen that they are approximately the same, with some to one place of decimal while some to two places of decimals.

Figure 2(d) shows that not all can satisfy power law.

Table 3(e) shows that the correlations decrease with the increase in $\mathrm{RH}$, but increase with the increase in the power of the polynomials.

Comparing the coefficients in Tables 3(e) and (f) it can be observed that they are approximately the same with some to two places of decimals while some to four places of decimals.

Figure 2(e) is almost the inverse of Figure 2(d).

Table 3(g) shows very good correlations between, and the correlation increases with the increase in the power of the polynomials.

Comparing Tables 3(g) and (h), the linear part shows that at $0 \%, 50 \%$ and $70 \% \mathrm{RH}$, they are the same to one place of decimal places. After that they are completely different.

Comparing Figures 3(a) and 2(a) it can be observed that they are similar.

Table 4(a) shows very good correlations for all the polynomials, and the correlations increase with the increase in the powers of the polynomials.

From Figure 3(b), the plots barely obey power law.

Table 4(b) shows that the correlations decrease with the increase in $\mathrm{RH}$, but increase with the increase in the power of the polynomials.

Comparing Figures 3(c) and 2(c) it can be observed that they are similar.

Table 4(c) shows very good correlations, and the correlations increases with the increase in the power of the polynomials.

From Table 4(d) it can be seen that the coefficients are approximately the same to one place of decimal and some to two places of decimals.

Figure 3(d) shows that power law is not obeyed.

Table 4(e) shows that there are poor correlations in the linear part, but the correlation improves with the increase in the power of the polynomials.

Comparing the coefficients of Tables 4(e) and (f) it can be observed that they are all approximately the same within two places of decimals, while some to four places of decimals.

Figure 3(e), is the inverse of Figure 3(d) and the power law is not obeyed.

Table 4(g) shows that there are poor correlations in the linear part, but the correlation improves with the increase in the power of the polynomials.

Comparing the coefficients of Tables $\mathbf{4}(\mathrm{g})$ and (h) it 


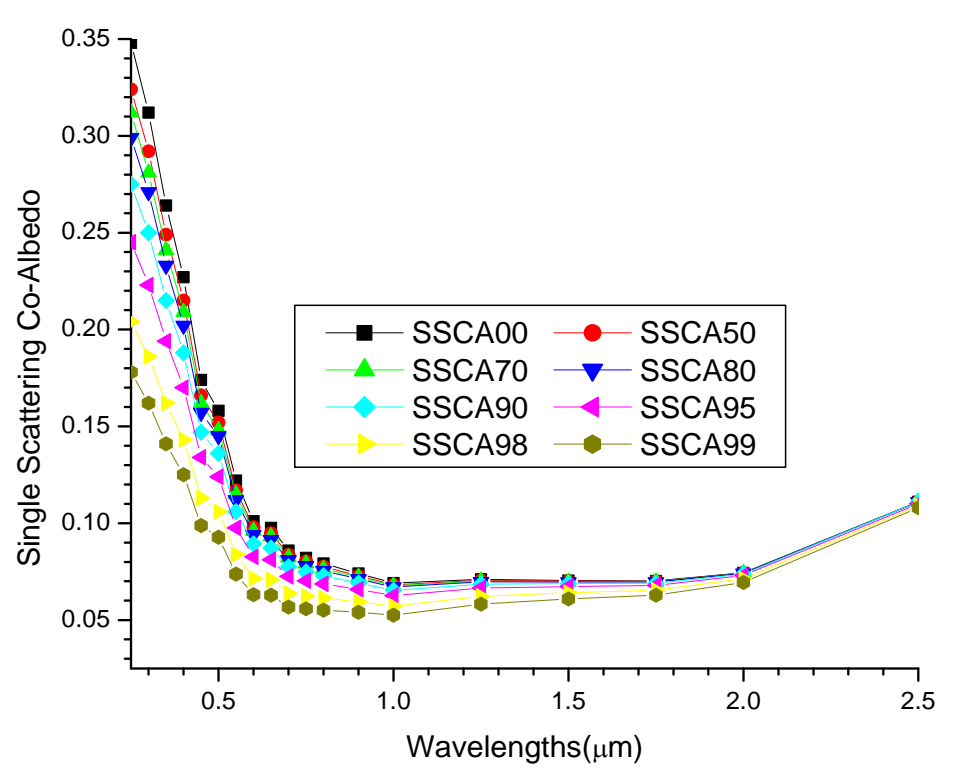

Figure 1(e). A graph of single scattering co-albedo against wavelength for sahara at RHs $0 \%, 50 \%, 70 \%, 80 \%, 90 \%, 95 \%$, $98 \%$ and $99 \%$.

Table 2(g). The results of the Angstrom coefficients of single scattering co-albedo using Equations (5), (6) and (10) for sahara model at the respective relative humidities using regression analysis with SPSS16.0.

\begin{tabular}{ccccccccccc}
\hline RH & \multicolumn{2}{c}{ Linear Equation (5) } & \multicolumn{3}{c}{ Quadratic Equation (6) } & \multicolumn{5}{c}{ Cubic Equation (10) } \\
\hline$(\%)$ & $\mathrm{R}^{2}$ & $\alpha$ & $\mathrm{R}^{2}$ & $\alpha_{1}$ & $\alpha_{2}$ & $\mathrm{R}^{2}$ & $\alpha_{1}$ & $\alpha_{2}$ & $\alpha_{3}$ \\
\hline 0 & 0.6604 & 0.6854 & 0.9563 & -0.3730 & 0.6800 & 0.9820 & -0.5976 & 0.9363 & 0.3359 \\
50 & 0.6450 & 0.6510 & 0.9521 & -0.3451 & 0.6658 & 0.9803 & -0.5714 & 0.9240 & 0.3385 \\
70 & 0.6342 & 0.6308 & 0.9511 & -0.3271 & 0.6610 & 0.9795 & -0.5488 & 0.9139 & 0.3315 \\
80 & 0.6242 & 0.6101 & 0.9499 & -0.3100 & 0.6532 & 0.9787 & -0.5278 & 0.9018 & 0.3258 \\
90 & 0.5946 & 0.5710 & 0.9481 & -0.2711 & 0.6527 & 0.9774 & -0.4818 & 0.8930 & 0.3151 \\
95 & 0.5480 & 0.5172 & 0.9427 & -0.2183 & 0.6507 & 0.9743 & -0.4247 & 0.8863 & 0.3088 \\
98 & 0.4483 & 0.4324 & 0.9379 & -0.1246 & 0.6699 & 0.9695 & -0.3150 & 0.8871 & 0.2848 \\
99 & 0.3625 & 0.3721 & 0.9352 & -0.0536 & 0.6932 & 0.9654 & -0.2319 & 0.8966 & 0.2666 \\
\hline
\end{tabular}

Table 2(h). The results of the Angstrom coefficients of single scattering co-albedo using Equation (3) for sahara model at the respective relative humidities.

\begin{tabular}{ccccccc}
\hline RH & Linear & \multicolumn{2}{c}{ Quadratic } & \multicolumn{2}{c}{ Cubic } \\
\hline$(\%)$ & $\alpha$ & $\alpha_{1}$ & $\alpha_{2}$ & $\alpha_{1}$ & $\alpha_{2}$ & $\alpha_{3}$ \\
\hline 0 & 0.68333 & -0.37147 & 0.678817 & -0.59818 & 0.937478 & 0.339073 \\
50 & 0.64979 & -0.3433 & 0.667123 & -0.56704 & 0.922397 & 0.334632 \\
70 & 0.631366 & -0.32723 & 0.662004 & -0.54863 & 0.914611 & 0.331136 \\
80 & 0.61253 & -0.3103 & 0.657862 & -0.52921 & 0.907625 & 0.327408 \\
90 & 0.571652 & -0.27204 & 0.652168 & -0.48483 & 0.894952 & 0.31826 \\
95 & 0.51703 & -0.21752 & 0.65193 & -0.42055 & 0.883569 & 0.30365 \\
98 & 0.431835 & -0.12473 & 0.668464 & -0.31204 & 0.882169 & 0.280141 \\
99 & 0.370726 & -0.0523 & 0.693104 & -0.22958 & 0.895362 & 0.265135 \\
\hline
\end{tabular}




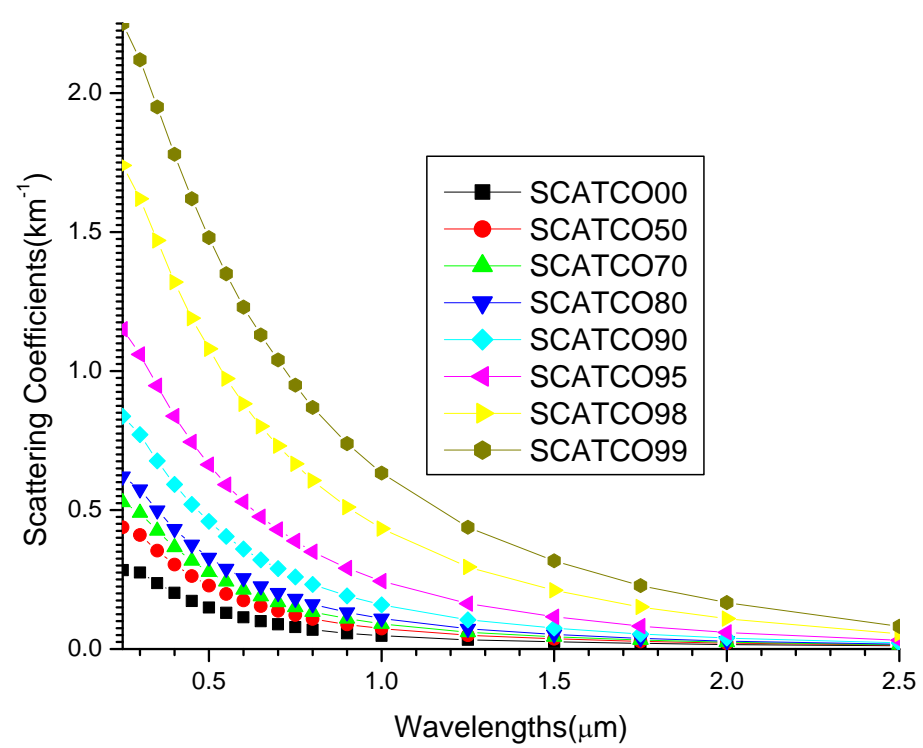

Figure 2(a). A graph of scattering coefficients against wavelength for urban at RHs $0 \%, 50 \%, 70 \%, 80 \%, 90 \%, 95 \%, 98 \%$ and $99 \%$.

Table 3(a). The results of the Angstrom coefficients of scattering coefficients using Equations (5), (6) and (10) for urban model at the respective relative humidities using regression analysis with SPSS16.0.

\begin{tabular}{|c|c|c|c|c|c|c|c|c|c|}
\hline \multirow{2}{*}{$\begin{array}{l}\mathrm{RH} \\
(\%)\end{array}$} & \multicolumn{2}{|c|}{ Linear Equation (5) } & \multicolumn{3}{|c|}{ Quadratic Equation (6) } & \multicolumn{4}{|c|}{ Cubic Equation (10) } \\
\hline & $\mathrm{R}^{2}$ & $\alpha$ & $\mathrm{R}^{2}$ & $\alpha_{1}$ & $\alpha_{2}$ & $\mathrm{R}^{2}$ & $\alpha_{1}$ & $\alpha_{2}$ & $\alpha_{3}$ \\
\hline 0 & 0.9906 & 1.5018 & 0.9961 & -1.5781 & -0.1661 & 0.9993 & -1.7201 & -0.0041 & 0.2124 \\
\hline 50 & 0.9853 & 1.5793 & 0.9986 & -1.7040 & -0.2714 & 0.9997 & -1.7925 & -0.1704 & 0.1324 \\
\hline 70 & 0.9816 & 1.5962 & 0.9992 & -1.7416 & -0.3165 & 0.9998 & -1.8045 & -0.2447 & 0.0941 \\
\hline 80 & 0.9779 & 1.6022 & 0.9995 & -1.7647 & -0.3537 & 0.9998 & -1.8060 & -0.3065 & 0.0618 \\
\hline 90 & 0.9698 & 1.5917 & 0.9997 & -1.7820 & -0.4143 & 0.9997 & -1.7851 & -0.4107 & 0.0047 \\
\hline 95 & 0.9602 & 1.5506 & 0.9995 & -1.7641 & -0.4648 & 0.9996 & -1.7325 & -0.5008 & -0.0473 \\
\hline 98 & 0.9469 & 1.4597 & 0.9988 & -1.6925 & -0.5067 & 0.9995 & -1.6291 & -0.5791 & -0.0948 \\
\hline 99 & 0.9373 & 1.3840 & 0.9983 & -1.6243 & -0.5231 & 0.9993 & -1.5473 & -0.6109 & -0.1151 \\
\hline
\end{tabular}

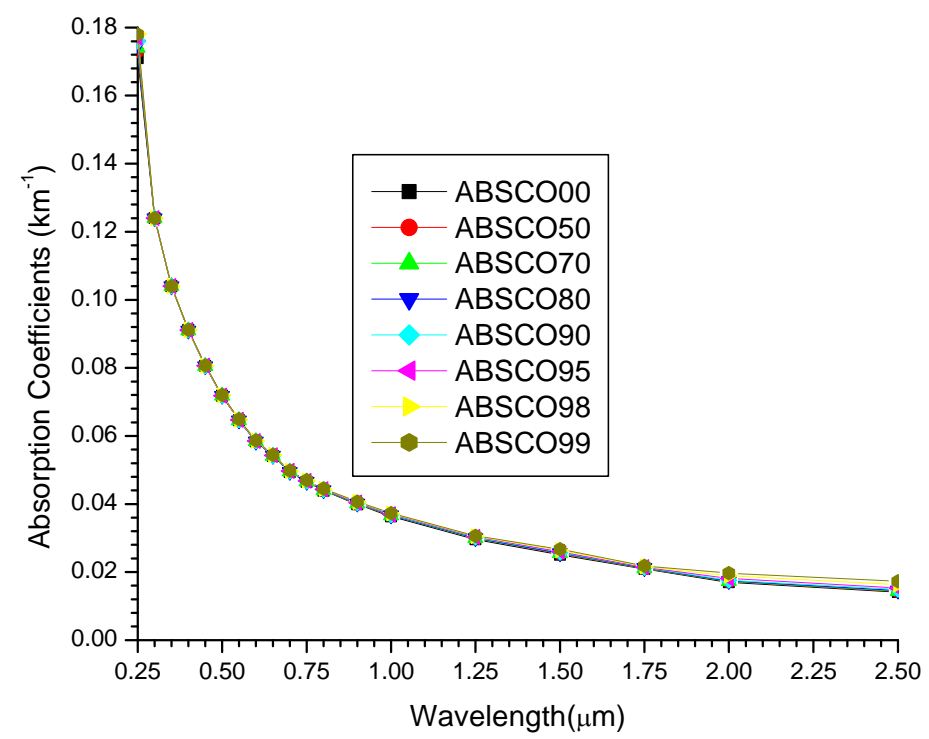

Figure 2(b). A graph of absorption coefficients against wavelength for urban at RHs $0 \%, 50 \%, 70 \%, 80 \%, 90 \%, 95 \%, 98 \%$ and $99 \%$. 
Table 3(b). The results of the Angstrom coefficients of absorption coefficients using Equations (5), (6) and (10) for urban model at the respective relative humidities using regression analysis with SPSS16.0.

\begin{tabular}{ccccccccccc}
\hline RH & \multicolumn{2}{c}{ Linear } & \multicolumn{3}{c}{ Quadratic } & \multicolumn{3}{c}{ Cubic } \\
\hline$(\%)$ & $\mathrm{R}^{2}$ & $\alpha$ & $\mathrm{R}^{2}$ & $\alpha_{1}$ & $\alpha_{2}$ & $\mathrm{R}^{2}$ & $\alpha_{1}$ & $\alpha_{2}$ & $\alpha_{3}$ \\
\hline 0 & 0.9958 & 1.0326 & 0.9971 & -1.0072 & 0.0554 & 0.9989 & -0.9344 & -0.0277 & -0.1089 \\
50 & 0.9951 & 1.0269 & 0.9967 & -0.9984 & 0.0620 & 0.9988 & -0.9207 & -0.0267 & -0.1163 \\
70 & 0.9948 & 1.0242 & 0.9966 & -0.9941 & 0.0655 & 0.9987 & -0.9156 & -0.0241 & -0.1174 \\
80 & 0.9945 & 1.0216 & 0.9966 & -0.9900 & 0.0688 & 0.9987 & -0.9112 & -0.0211 & -0.1178 \\
90 & 0.9940 & 1.0157 & 0.9965 & -0.9806 & 0.0763 & 0.9986 & -0.9029 & -0.0123 & -0.1162 \\
95 & 0.9932 & 1.0067 & 0.9966 & -0.9664 & 0.0877 & 0.9986 & -0.8925 & 0.0034 & -0.1105 \\
98 & 0.9914 & 0.9889 & 0.9970 & -0.9385 & 0.1097 & 0.9984 & -0.8756 & 0.0380 & -0.0940 \\
99 & 0.9892 & 0.9716 & 0.9973 & -0.9117 & 0.1304 & 0.9982 & -0.8618 & 0.0734 & -0.0746 \\
\hline
\end{tabular}

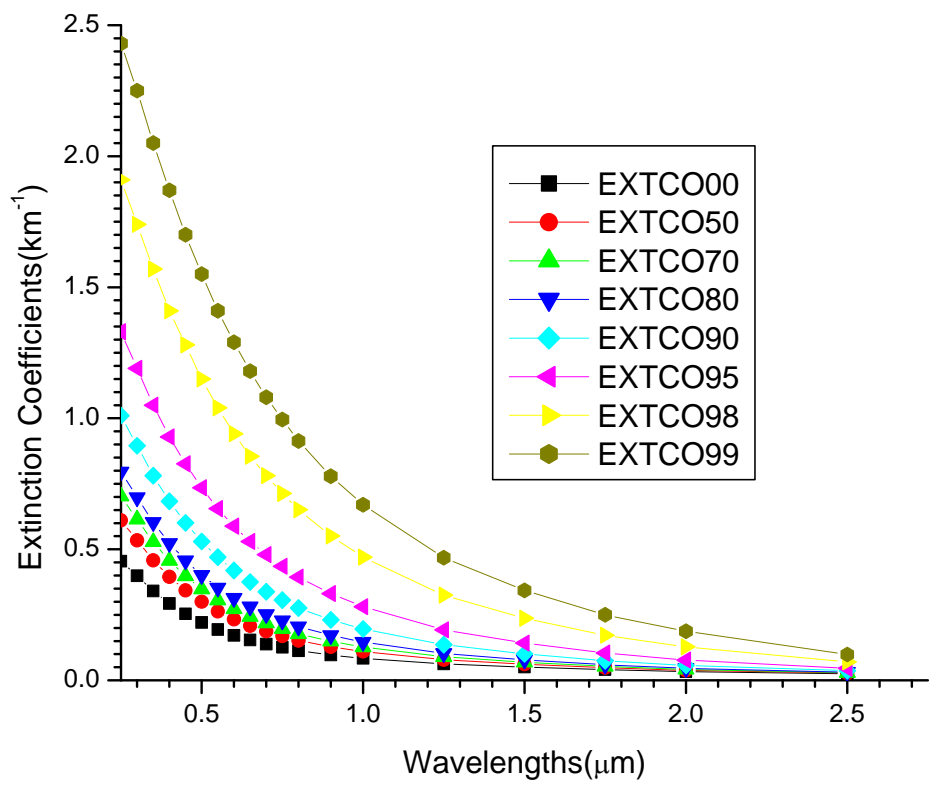

Figure 2(c). A graph of extinction coefficients against wavelength for urban at RHs $\mathbf{0 \% , 5 0 \% , 7 0 \% , 8 0 \% , 9 0 \% , 9 5 \% , 9 8 \% ~}$ and $99 \%$.

Table 3(c). The results of the Angstrom coefficients of extinction coefficients using Equations (5), (6) and (10) for urban model at the respective relative humidities using regression analysis with SPSS16.0.

\begin{tabular}{cccccccccc}
\hline $\mathrm{RH}$ & \multicolumn{2}{c}{ Linear Equation (5) } & \multicolumn{3}{c}{ Quadratic Equation (6) } & \multicolumn{4}{c}{ Cubic Equation (10) } \\
\hline$(\%)$ & $\mathrm{R}^{2}$ & $\alpha$ & $\mathrm{R}^{2}$ & $\alpha_{1}$ & $\alpha_{2}$ & $\mathrm{R}^{2}$ & $\alpha_{1}$ & $\alpha_{2}$ & $\alpha_{3}$ \\
\hline 0 & 0.9975 & 1.3058 & 0.9985 & -1.3332 & -0.0597 & 0.9995 & -1.4040 & 0.0210 & 0.1058 \\
50 & 0.9946 & 1.3899 & 0.9991 & -1.4535 & -0.1384 & 0.9998 & -1.5150 & -0.0682 & 0.0920 \\
70 & 0.9921 & 1.4196 & 0.9993 & -1.5021 & -0.1795 & 0.9998 & -1.5555 & -0.1185 & 0.0800 \\
80 & 0.9893 & 1.4403 & 0.9995 & -1.5402 & -0.2176 & 0.9999 & -1.5843 & -0.1674 & 0.0659 \\
90 & 0.9824 & 1.4620 & 0.9998 & -1.5947 & -0.2889 & 0.9999 & -1.6166 & -0.2640 & 0.0327 \\
95 & 0.9728 & 1.4572 & 0.9999 & -1.6229 & -0.3607 & 0.9999 & -1.6168 & -0.3676 & -0.0090 \\
98 & 0.9579 & 1.4055 & 0.9995 & -1.6049 & -0.4340 & 0.9998 & -1.5647 & -0.4799 & -0.0601 \\
99 & 0.9472 & 1.3480 & 0.9990 & -1.5627 & -0.4673 & 0.9996 & -1.5047 & -0.5335 & -0.0868 \\
\hline
\end{tabular}


Table 3(d). The results of the Angstrom coefficients of extinction coefficients using Equations (1), (7), (9) and (12) for urban model at the respective relative humidities using regression analysis with SPSS16.0.

\begin{tabular}{ccccccc}
\hline RH & \multicolumn{2}{c}{ Linear } & \multicolumn{2}{c}{ Quadratic } & \multicolumn{2}{c}{ Cubic } \\
\hline$(\%)$ & Equation (7) & Equation (1) & Equation (9) & Equation (1) & Equation (12) & Equation (1) \\
\hline 0 & $\alpha$ & $\alpha$ & $\alpha_{1}(\lambda)$ & $\alpha_{1}(\lambda)$ & $\alpha_{2}(\lambda)$ & $\alpha_{2}(\lambda)$ \\
\hline 50 & 1.305762 & 1.317118 & 1.296971 & 1.285558 & 1.260416 & 1.267717 \\
70 & 1.389882 & 1.408679 & 1.369510 & 1.351385 & 1.337729 & 1.344704 \\
80 & 1.419598 & 1.440412 & 1.393177 & 1.372674 & 1.365554 & 1.371538 \\
90 & 1.440264 & 1.462055 & 1.408237 & 1.386470 & 1.385480 & 1.390167 \\
95 & 1.461972 & 1.483500 & 1.419447 & 1.397601 & 1.408146 & 1.410535 \\
98 & 1.457184 & 1.475636 & 1.404097 & 1.384973 & 1.407222 & 1.407436 \\
99 & 1.405514 & 1.418383 & 1.341632 & 1.328506 & 1.362398 & 1.361215 \\
\hline
\end{tabular}

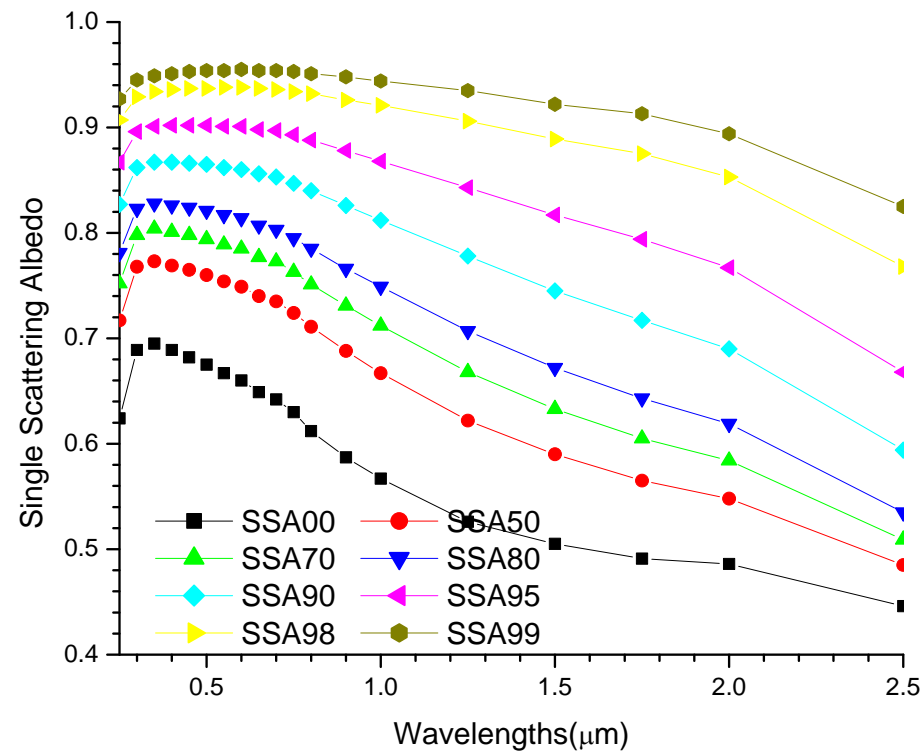

Figure 2(d). A graph of single scattering albedo against wavelength for urban at RHs $0 \%, 50 \%, 70 \%, 80 \%, 90 \%, 95 \%, 98 \%$ and $99 \%$.

Table 3(e). The results of the Angstrom coefficients of single scattering albedo using Equations (5), (6) and (10) for urban model at the respective relative humidities using regression analysis with SPSS16.0.

\begin{tabular}{cccccccccc}
\hline RH & \multicolumn{2}{c}{ Linear Equation (5) } & \multicolumn{3}{c}{ Quadratic Equation (6) } & \multicolumn{4}{c}{ Cubic Equation (10) } \\
\hline$(\%)$ & $\mathrm{R}^{2}$ & $\alpha$ & $\mathrm{R}^{2}$ & $\alpha_{1}$ & $\alpha_{2}$ & $\mathrm{R}^{2}$ & $\alpha_{1}$ & $\alpha_{2}$ & $\alpha_{3}$ \\
\hline 0 & 0.8376 & 0.1961 & 0.9498 & -0.2450 & -0.1064 & 0.9898 & -0.3162 & -0.0252 & 0.1064 \\
50 & 0.8070 & 0.1893 & 0.9884 & -0.2505 & -0.1331 & 0.9942 & -0.2772 & -0.1026 & 0.0400 \\
70 & 0.7798 & 0.1766 & 0.9933 & -0.2396 & -0.1370 & 0.9942 & -0.2491 & -0.1261 & 0.0143 \\
80 & 0.7515 & 0.1620 & 0.9931 & -0.2246 & -0.1362 & 0.9932 & -0.2216 & -0.1396 & -0.0044 \\
90 & 0.6908 & 0.1297 & 0.9836 & -0.1872 & -0.1252 & 0.9890 & -0.1682 & -0.1469 & -0.0285 \\
95 & 0.6169 & 0.0935 & 0.9637 & -0.1412 & -0.1039 & 0.9806 & -0.1155 & -0.1331 & -0.0384 \\
98 & 0.5108 & 0.0542 & 0.9320 & -0.0877 & -0.0729 & 0.9656 & -0.0646 & -0.0993 & -0.0345 \\
99 & 0.4347 & 0.0359 & 0.9104 & -0.0615 & -0.0557 & 0.9540 & -0.0426 & -0.0772 & -0.0283 \\
\hline
\end{tabular}


Table 3(f). The results of the Angstrom coefficients of single scattering albedo using Equation (2) for urban model at the respective relative humidities.

\begin{tabular}{ccccccc}
\hline RH & Linear & \multicolumn{2}{c}{ Quadratic } & \multicolumn{2}{c}{ Cubic } \\
\hline$(\%)$ & $\alpha$ & $\alpha_{1}$ & $\alpha_{2}$ & $\alpha_{1}$ & $\alpha_{2}$ & $\alpha_{3}$ \\
\hline 0 & 0.196057 & -0.244939 & -0.106400 & -0.316179 & -0.025120 & 0.106549 \\
50 & 0.189424 & -0.250513 & -0.132973 & -0.277519 & -0.102162 & 0.040390 \\
70 & 0.176572 & -0.239505 & -0.136985 & -0.248942 & -0.126217 & 0.014115 \\
80 & 0.161910 & -0.224417 & -0.136057 & -0.221713 & -0.139142 & -0.004044 \\
90 & 0.129716 & -0.187304 & -0.125352 & -0.168540 & -0.146761 & -0.028065 \\
95 & 0.093392 & -0.141213 & -0.104091 & -0.115660 & -0.133245 & -0.038218 \\
98 & 0.054221 & -0.087622 & -0.072703 & -0.064399 & -0.099199 & -0.034733 \\
99 & 0.035931 & -0.061562 & -0.055790 & -0.042615 & -0.077408 & -0.028338 \\
\hline
\end{tabular}

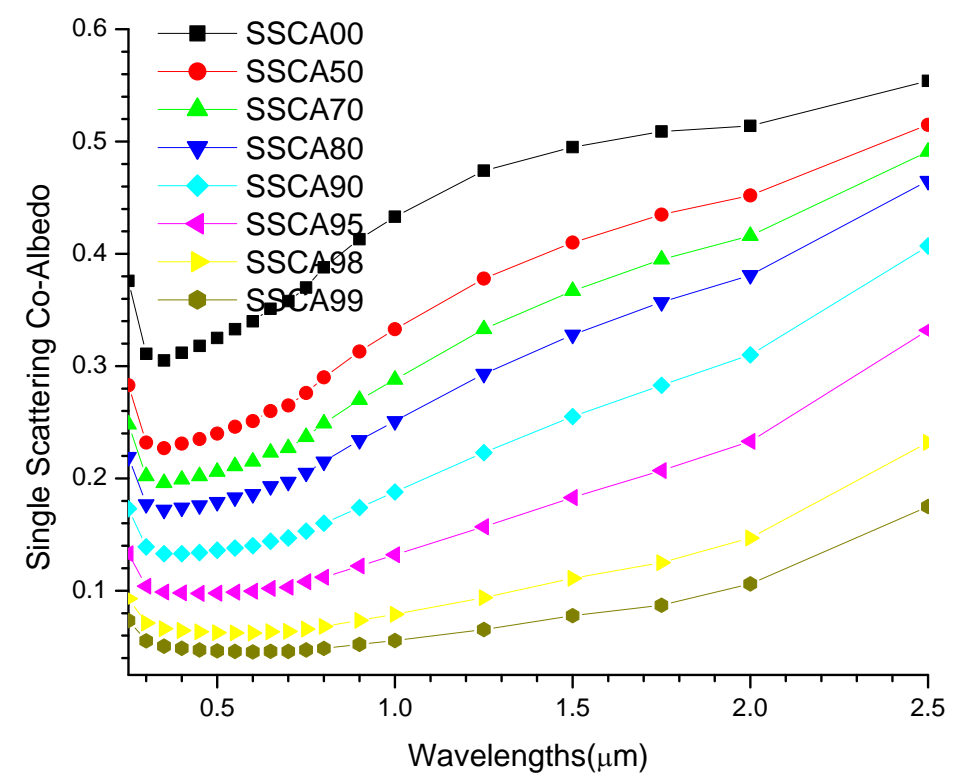

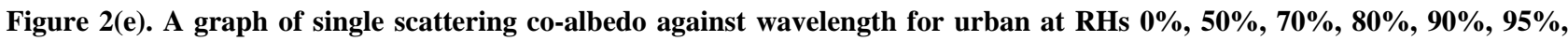
$98 \%$ and $99 \%$.

Table 3(g). The results of the Angstrom coefficients of single scattering co-albedo using Equations (5), (6) and (10) for urban model at the respective relative humidities using regression analysis with SPSS16.0.

\begin{tabular}{ccccccccccc}
\hline RH & \multicolumn{2}{c}{ Linear Equation (5) } & \multicolumn{3}{c}{ Quadratic Equation (6) } & \multicolumn{5}{c}{ Cubic Equation (10) } \\
\hline$(\%)$ & $\mathrm{R}^{2}$ & $\alpha$ & $\mathrm{R}^{2}$ & $\alpha_{1}$ & $\alpha_{2}$ & $\mathrm{R}^{2}$ & $\alpha_{1}$ & $\alpha_{2}$ & $\alpha_{3}$ \\
\hline 0 & 0.8636 & -0.2906 & 0.8981 & 0.5267 & -0.0928 & 0.9096 & 0.1643 & 0.2374 & -0.0831 \\
50 & 0.9171 & -0.3964 & 0.9780 & 0.5457 & -0.0587 & 0.9425 & -0.0459 & 0.4805 & -0.1357 \\
70 & 0.9291 & -0.4395 & 0.9313 & 0.5270 & -0.0344 & 0.9508 & -0.1609 & 0.5924 & -0.1577 \\
80 & 0.9327 & -0.4714 & 0.9327 & 0.4762 & -0.0019 & 0.9548 & -0.3073 & 0.7121 & -0.1796 \\
90 & 0.9258 & -0.5157 & 0.9320 & 0.3446 & 0.0673 & 0.9585 & -0.5964 & 0.9248 & -0.2158 \\
95 & 0.8984 & -0.5383 & 0.9292 & 0.1331 & 0.1593 & 0.9593 & -0.9312 & 1.1292 & -0.2440 \\
98 & 0.8247 & -0.5262 & 0.9197 & 0.1593 & 0.2855 & 0.9562 & -1.3954 & 1.3749 & -0.2741 \\
99 & 0.7478 & -0.4986 & 0.9077 & 0.2855 & 0.0695 & 0.9510 & -1.7342 & 1.5489 & -0.2970 \\
\hline
\end{tabular}


Table 3(h). The results of the Angstrom coefficients of single scattering co-albedo using Equation (3) for urban model at the respective relative humidities.

\begin{tabular}{|c|c|c|c|c|c|c|}
\hline \multirow{2}{*}{$\begin{array}{l}\mathrm{RH} \\
(\%)\end{array}$} & \multirow{2}{*}{$\begin{array}{c}\text { Linear } \\
\qquad \alpha\end{array}$} & \multicolumn{2}{|c|}{ Quadratic } & \multicolumn{3}{|c|}{ Cubic } \\
\hline & & $\alpha_{1}$ & $\alpha_{2}$ & $\alpha_{1}$ & $\alpha_{2}$ & $\alpha_{3}$ \\
\hline 0 & -0.273154 & 0.326035 & 0.115104 & 0.469589 & -0.048684 & -0.214705 \\
\hline 50 & -0.362993 & 0.455074 & 0.200432 & 0.594301 & 0.041582 & -0.208233 \\
\hline 70 & -0.395439 & 0.508002 & 0.245014 & 0.639970 & 0.094445 & -0.197376 \\
\hline 80 & -0.418647 & 0.550228 & 0.286412 & 0.673048 & 0.146282 & -0.183694 \\
\hline 90 & -0.446297 & 0.614085 & 0.365224 & 0.713632 & 0.251647 & -0.148885 \\
\hline 95 & -0.450505 & 0.656495 & 0.448377 & 0.724332 & 0.370979 & -0.101459 \\
\hline 98 & -0.416653 & 0.666450 & 0.543730 & 0.689108 & 0.517878 & -0.033888 \\
\hline 99 & -0.376471 & 0.651039 & 0.597649 & 0.642886 & 0.606951 & 0.012194 \\
\hline
\end{tabular}

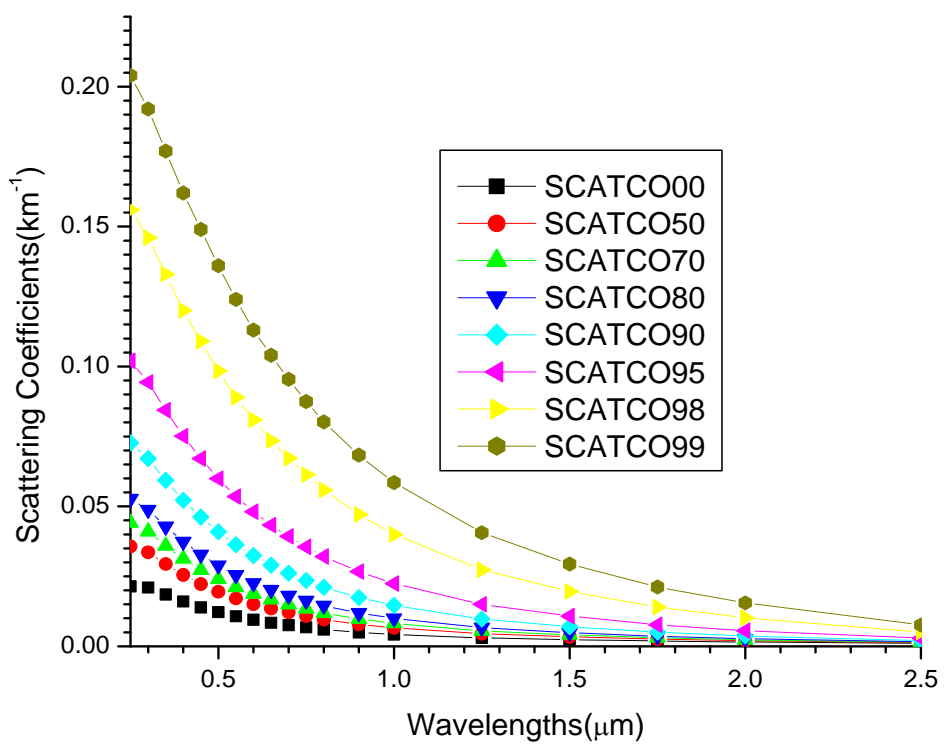

Figure 3(a). A graph of scattering coefficients against wavelength for continental clean at RHs $0 \%, 50 \%, 70 \%, 80 \%, 90 \%$, $\mathbf{9 5 \%}, \mathbf{9 8 \%}$ and $99 \%$.

Table 4(a). The results of the Angstrom coefficients of scattering coefficients using Equations (5), (6) and (10) for continental clean model at the respective relative humidities using regression analysis with SPSS16.0.

\begin{tabular}{cccccccccc}
\hline $\mathrm{RH}$ & \multicolumn{2}{c}{ Linear Equation (5) } & \multicolumn{3}{c}{ Quadratic Equation (6) } & \multicolumn{3}{c}{ Cubic Equation (10) } \\
\hline$(\%)$ & $\mathrm{R}^{2}$ & $\alpha$ & $\mathrm{R}^{2}$ & $\alpha_{1}$ & $\alpha_{2}$ & $\mathrm{R}^{2}$ & $\alpha_{1}$ & $\alpha_{2}$ & $\alpha_{3}$ \\
\hline 0 & 0.9887 & 1.3858 & 0.9956 & -1.4647 & -0.1718 & 0.9991 & -1.6016 & -0.0156 & 0.2048 \\
50 & 0.9839 & 1.5029 & 0.9985 & -1.6276 & -0.2715 & 0.9997 & -1.7142 & -0.1727 & 0.1295 \\
70 & 0.9802 & 1.5327 & 0.9992 & -1.6781 & -0.3164 & 0.9998 & -1.7403 & -0.2454 & 0.0931 \\
80 & 0.9763 & 1.5483 & 0.9995 & -1.7108 & -0.3537 & 0.9998 & -1.7522 & -0.3065 & 0.0619 \\
90 & 0.9682 & 1.5522 & 0.9998 & -1.7429 & -0.4151 & 0.9998 & -1.7469 & -0.4106 & 0.0060 \\
95 & 0.9586 & 1.5227 & 0.9995 & -1.7371 & -0.4666 & 0.9997 & -1.7067 & -0.5013 & -0.0455 \\
98 & 0.9451 & 1.4423 & 0.9988 & -1.6764 & -0.5096 & 0.9995 & -1.6141 & -0.5807 & -0.0933 \\
99 & 0.9356 & 1.3710 & 0.9983 & -1.6127 & -0.5260 & 0.9993 & -1.5366 & -0.6129 & -0.1138 \\
\hline
\end{tabular}




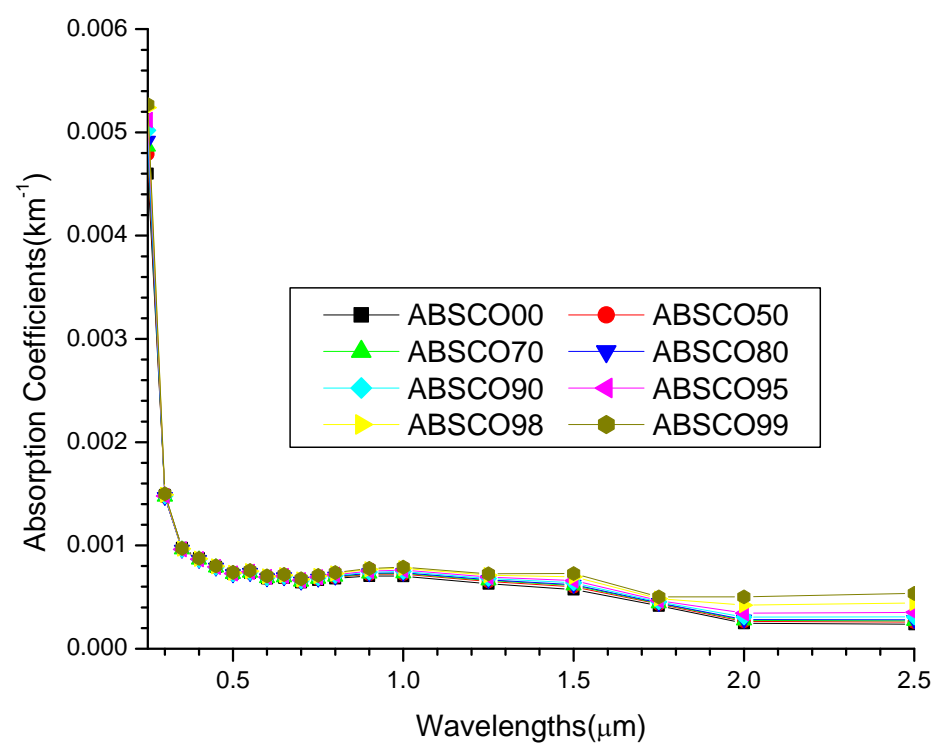

Figure 3(b). A graph of absorption coefficients against wavelength for continental clean at RHs $0 \%, 50 \%, 70 \%, 80 \%, 90 \%$, $95 \%, 98 \%$ and $99 \%$.

Table 4(b). The results of the Angstrom coefficients of absorption coefficients using Equations (5), (6) and (10) for continental clean model at the respective relative humidities using regression analysis with SPSS16.0.

\begin{tabular}{cccccccccc}
\hline RH & \multicolumn{2}{c}{ Linear } & \multicolumn{3}{c}{ Quadratic } & \multicolumn{3}{c}{ Cubic } \\
\hline$(\%)$ & $\mathrm{R}^{2}$ & $\alpha$ & $\mathrm{R}^{2}$ & $\alpha_{1}$ & $\alpha_{2}$ & $\mathrm{R}^{2}$ & $\alpha_{1}$ & $\alpha_{2}$ & $\alpha_{3}$ \\
\hline 0 & 0.7321 & 0.8145 & 0.7574 & -0.7114 & 0.2243 & 0.9472 & -0.0227 & -0.5615 & -1.0300 \\
50 & 0.6988 & 0.7801 & 0.7326 & -0.6633 & 0.2542 & 0.9397 & 0.0419 & -0.5504 & -1.0547 \\
70 & 0.6866 & 0.7655 & 0.7252 & -0.6419 & 0.2690 & 0.9368 & 0.0638 & -0.5362 & -1.0555 \\
80 & 0.6757 & 0.7518 & 0.7195 & -0.6214 & 0.2838 & 0.9343 & 0.0824 & -0.5193 & -1.0527 \\
90 & 0.6537 & 0.7228 & 0.7108 & -0.5773 & 0.3168 & 0.9293 & 0.1166 & -0.4749 & -1.0378 \\
95 & 0.6226 & 0.6824 & 0.7026 & -0.5158 & 0.3626 & 0.9219 & 0.1567 & -0.4047 & -1.0058 \\
98 & 0.5596 & 0.6126 & 0.6940 & -0.4082 & 0.4450 & 0.9083 & 0.2214 & -0.2733 & -0.9416 \\
99 & 0.4973 & 0.5532 & 0.6912 & -0.3180 & 0.5120 & 0.8954 & 0.2707 & -0.1597 & -0.8805 \\
\hline
\end{tabular}

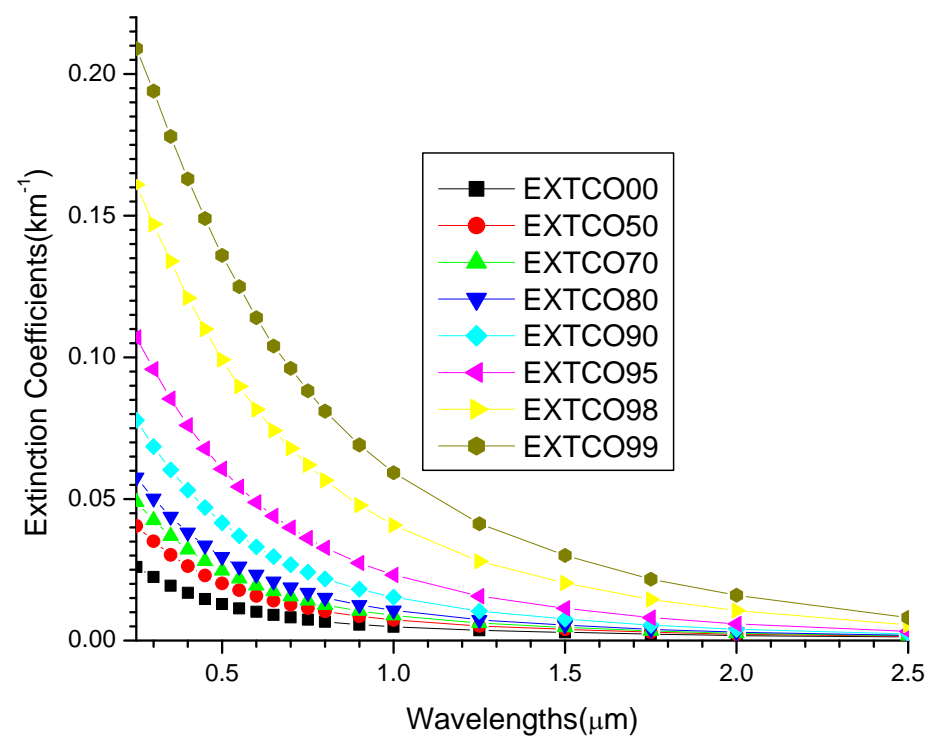

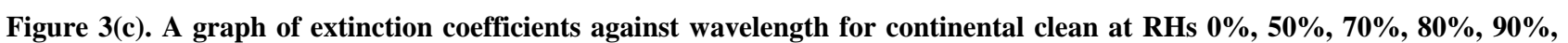
$95 \%, 98 \%$ and $99 \%$. 
Table 4(c). The results of the Angstrom coefficients of extinction coefficients using Equations (5), (6) and (10) for continental clean model at the respective relative humidities using regression analysis with SPSS16.0.

\begin{tabular}{cccccccccc}
\hline $\mathrm{RH}$ & \multicolumn{2}{c}{ Linear Equation (5) } & \multicolumn{3}{c}{ Quadratic Equation (6) } & \multicolumn{4}{c}{ Cubic Equation (10) } \\
\hline$(\%)$ & $\mathrm{R}^{2}$ & $\alpha$ & $\mathrm{R}^{2}$ & $\alpha_{1}$ & $\alpha_{2}$ & $\mathrm{R}^{2}$ & $\alpha_{1}$ & $\alpha_{2}$ & $\alpha_{3}$ \\
\hline 0 & 0.9951 & 1.3264 & 0.9988 & -1.3815 & -0.1200 & 0.9993 & -1.4324 & -0.0620 & 0.0761 \\
50 & 0.9891 & 1.4450 & 0.9995 & -1.5460 & -0.2197 & 0.9997 & -1.5823 & -0.1782 & 0.0544 \\
70 & 0.9852 & 1.4790 & 0.9997 & -1.6010 & -0.2655 & 0.9998 & -1.6265 & -0.2364 & 0.0381 \\
80 & 0.9813 & 1.4991 & 0.9998 & -1.6390 & -0.3046 & 0.9998 & -1.6529 & -0.2888 & 0.0207 \\
90 & 0.9732 & 1.5122 & 0.9998 & -1.6827 & -0.3711 & 0.9999 & -1.6729 & -0.3822 & -0.0146 \\
95 & 0.9633 & 1.4924 & 0.9996 & -1.6898 & -0.4295 & 0.9998 & -1.6551 & -0.4691 & -0.0518 \\
98 & 0.9495 & 1.4220 & 0.9991 & -1.6432 & -0.4816 & 0.9997 & -1.5828 & -0.5505 & -0.0903 \\
99 & 0.9397 & 1.3554 & 0.9986 & -1.5864 & -0.5028 & 0.9995 & -1.5140 & -0.5853 & -0.1082 \\
\hline
\end{tabular}

Table 4(d). The results of the Angstrom coefficients of extinction coefficients using Equations (1), (7), (9) and (12) for continental clean model at the respective relative humidities using regression analysis with SPSS16.0.

\begin{tabular}{ccccccc}
\hline RH & \multicolumn{2}{c}{ Linear } & \multicolumn{2}{c}{ Quadratic } & \multicolumn{2}{c}{ Cubic } \\
\hline$(\%)$ & Equation (7) & Equation (1) & Equation (9) & Equation (1) & Equation $(12)$ & Equation $(1)$ \\
\hline 0 & $\alpha$ & $\alpha$ & $\alpha_{1}(\lambda)$ & $\alpha_{1}(\lambda)$ & $\alpha_{2}(\lambda)$ & $\alpha_{2}(\lambda)$ \\
\hline 50 & 1.326374 & 1.323762 & 1.308708 & 1.288183 & 1.282407 & 1.297761 \\
70 & 1.445043 & 1.446130 & 1.412712 & 1.390209 & 1.393925 & 1.411310 \\
80 & 1.478996 & 1.481190 & 1.439914 & 1.417335 & 1.426736 & 1.443978 \\
90 & 1.499053 & 1.501993 & 1.454219 & 1.432156 & 1.447062 & 1.463395 \\
95 & 1.512202 & 1.515944 & 1.457587 & 1.437578 & 1.462620 & 1.476845 \\
98 & 1.492423 & 1.496337 & 1.429202 & 1.412395 & 1.447108 & 1.458491 \\
99 & 1.421950 & 1.425678 & 1.351065 & 1.338642 & 1.382278 & 1.390248 \\
\hline
\end{tabular}

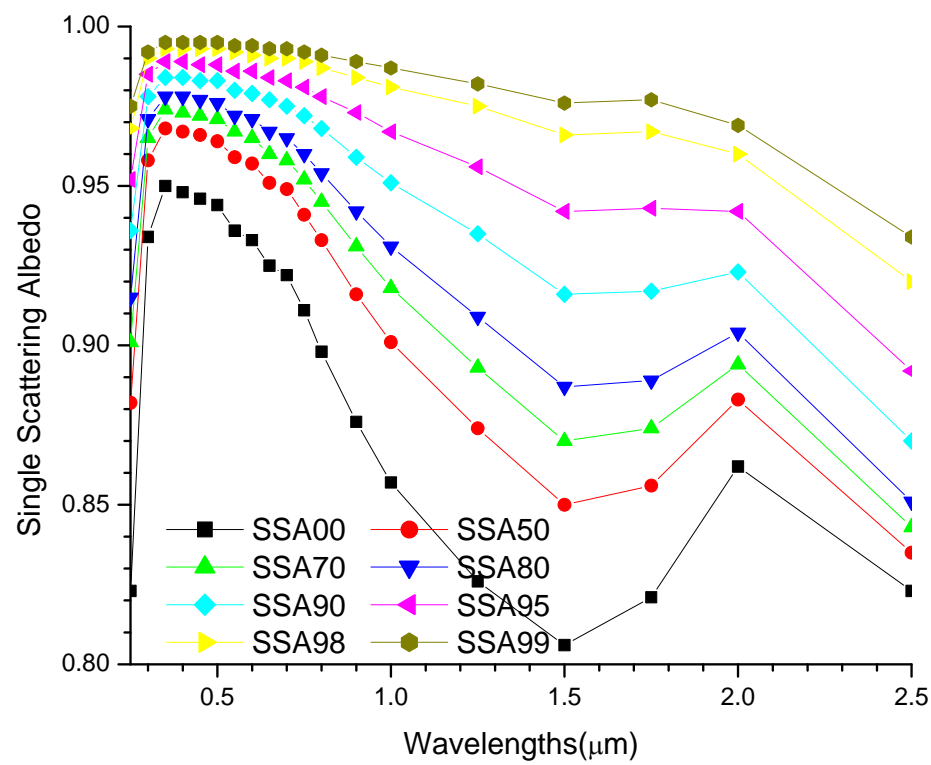

Figure 3(d). A graph of single scattering albedo against wavelength for continental clean at RHs $\mathbf{0 \%}, \mathbf{5 0} \%, \mathbf{7 0} \%, \mathbf{8 0} \%, \mathbf{9 0} \%$, $95 \%, 98 \%$ and $99 \%$. 
Table 4(e). The results of the Angstrom coefficients of single scattering albedousing Equations (5), (6) and (10) for continental clean model at the respective relative humidities using regression analysis with SPSS16.0.

\begin{tabular}{cccccccccc}
\hline $\mathrm{RH}$ & \multicolumn{1}{c}{ Linear Equation (5) } & \multicolumn{3}{c}{ Quadratic Equation (6) } & \multicolumn{5}{c}{ Cubic Equation (10) } \\
\hline$(\%)$ & $\mathrm{R}^{2}$ & $\alpha$ & $\mathrm{R}^{2}$ & $\alpha_{1}$ & $\alpha_{2}$ & $\mathrm{R}^{2}$ & $\alpha_{1}$ & $\alpha_{2}$ & $\alpha_{3}$ \\
\hline 0 & 0.4258 & 0.0592 & 0.5733 & -0.0830 & -0.0517 & 0.8994 & -0.1691 & 0.0465 & 0.1288 \\
50 & 0.5636 & 0.0578 & 0.7714 & -0.0817 & -0.0520 & 0.9251 & -0.1318 & 0.0052 & 0.0749 \\
70 & 0.5886 & 0.0537 & 0.8283 & -0.0771 & -0.0508 & 0.9299 & -0.1142 & -0.0085 & 0.0555 \\
80 & 0.5963 & 0.0493 & 0.8647 & -0.0718 & -0.0490 & 0.9317 & -0.0992 & -0.0177 & 0.0410 \\
90 & 0.5850 & 0.0400 & 0.9057 & -0.0602 & -0.0439 & 0.9300 & -0.0737 & -0.0285 & 0.0202 \\
95 & 0.5456 & 0.0303 & 0.9168 & -0.0472 & -0.0370 & 0.9205 & -0.0514 & -0.0323 & 0.0062 \\
98 & 0.4788 & 0.0202 & 0.9037 & -0.0331 & -0.0281 & 0.9053 & -0.0311 & -0.0303 & -0.0029 \\
99 & 0.4350 & 0.0155 & 0.8847 & -0.0262 & -0.0233 & 0.8939 & -0.0224 & -0.0276 & -0.0056 \\
\hline
\end{tabular}

Table 4(f). The results of the Angstrom coefficients of single scattering albedo using Equations (2) for continental clean model at the respective relative humidities.

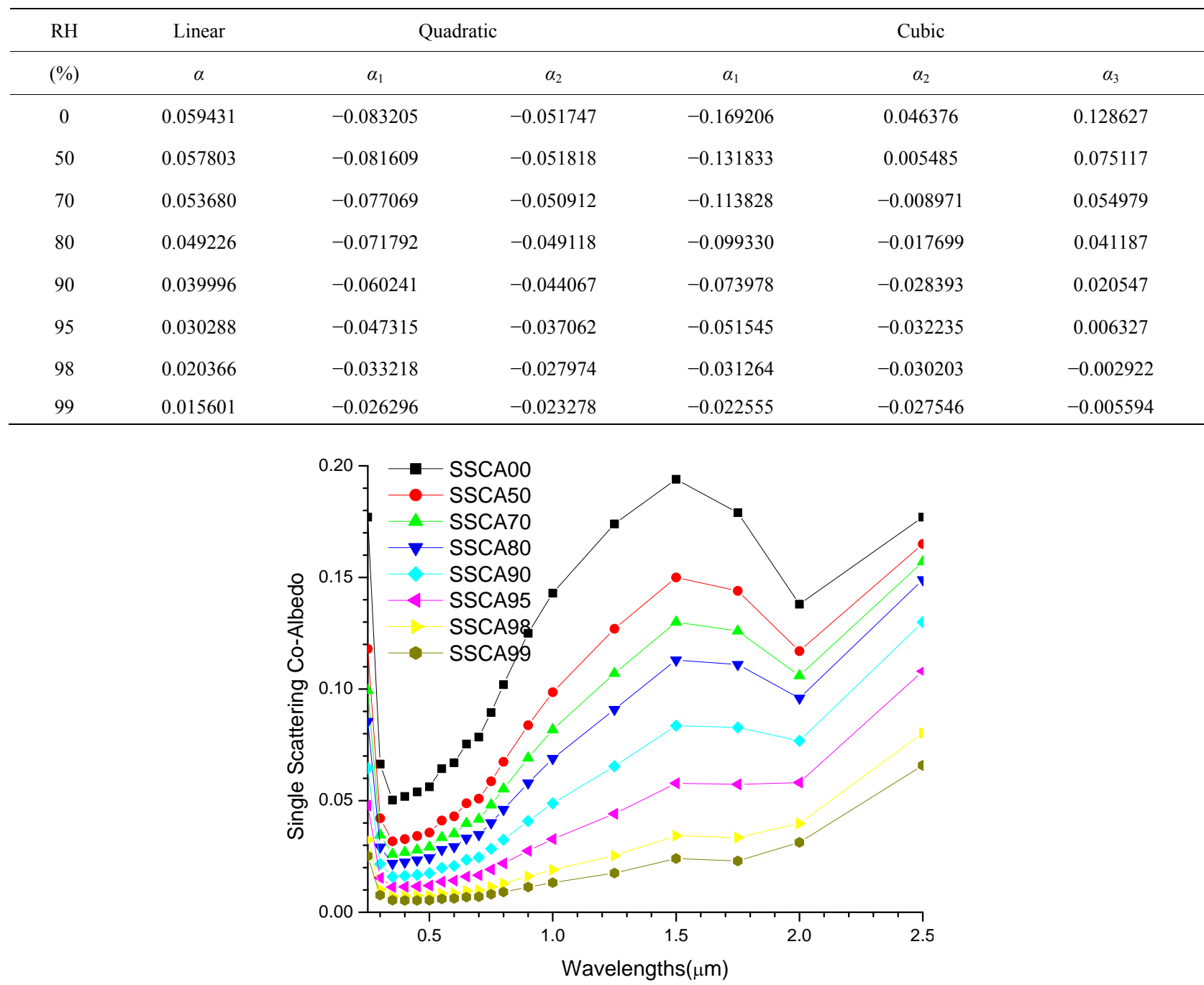

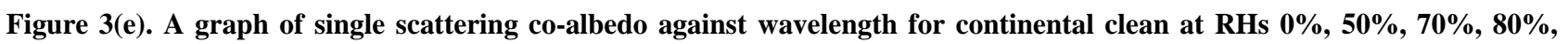
$90 \%, 95 \%, 98 \%$ and $99 \%$. 
Table 4(g). The results of the Angstrom coefficients of single scattering co-albedo using Equations (5), (6) and (10) for continental clean model at the respective relative humidities using regression analysis with SPSS16.0.

\begin{tabular}{cccccccccc}
\hline $\mathrm{RH}$ & \multicolumn{2}{c}{ Linear Equation (5) } & \multicolumn{3}{c}{ Quadratic Equation (6) } & \multicolumn{4}{c}{ Cubic Equation (10) } \\
\hline$(\%)$ & $\mathrm{R}^{2}$ & $\alpha$ & $\mathrm{R}^{2}$ & $\alpha_{1}$ & $\alpha_{2}$ & $\mathrm{R}^{2}$ & $\alpha_{1}$ & $\alpha_{2}$ & $\alpha_{3}$ \\
\hline 0 & 0.4639 & -0.5115 & 0.5585 & 0.6689 & 0.3425 & 0.9093 & 1.4075 & -0.5003 & -1.1048 \\
50 & 0.5534 & -0.6649 & 0.6829 & 0.8839 & 0.4767 & 0.9333 & 1.6267 & -0.3708 & -1.1109 \\
70 & 0.5742 & -0.7143 & 0.7200 & 0.9595 & 0.5337 & 0.9386 & 1.6912 & -0.3012 & -1.0944 \\
80 & 0.5820 & -0.7472 & 0.7475 & 1.0186 & 0.5907 & 0.9425 & 1.7369 & -0.2289 & -1.0743 \\
90 & 0.5831 & -0.7899 & 0.7850 & 1.1065 & 0.6890 & 0.9438 & 1.7909 & -0.0918 & -1.0236 \\
95 & 0.5671 & -0.8087 & 0.8147 & 1.1726 & 0.7921 & 0.9433 & 1.8121 & 0.0625 & -0.9564 \\
98 & 0.5308 & -0.8104 & 0.8471 & 1.2365 & 0.9275 & 0.9419 & 1.8051 & 0.2788 & -0.8504 \\
99 & 0.5013 & -0.8068 & 0.8635 & 1.2738 & 1.0165 & 0.9396 & 1.7958 & 0.4209 & -0.7808 \\
\hline
\end{tabular}

Table 4(h). The results of the Angstrom coefficients of single scattering co-albedo using Equation (3) for continental clean model at the respective relative humidities.

\begin{tabular}{ccccccc}
\hline RH & Linear & \multicolumn{2}{c}{ Quadratic } & \multicolumn{3}{c}{ Cubic } \\
\hline$(\%)$ & $\alpha$ & $\alpha_{1}$ & $\alpha_{2}$ & $\alpha_{1}$ & $\alpha_{2}$ & $\alpha_{3}$ \\
\hline 0 & -0.511894 & 0.670076 & 0.344312 & 1.409672 & -0.499528 & -1.106169 \\
50 & -0.664984 & 0.882661 & 0.473817 & 1.624198 & -0.372238 & -1.109071 \\
70 & -0.713497 & 0.959074 & 0.534546 & 1.690289 & -0.299732 & -1.093633 \\
80 & -0.747241 & 1.017557 & 0.588393 & 1.735258 & -0.230466 & -1.073422 \\
90 & -0.789407 & 1.105397 & 0.687812 & 1.789529 & -0.092746 & -1.023214 \\
95 & -0.810037 & 1.173939 & 0.792101 & 1.811768 & 0.064371 & -0.953962 \\
98 & -0.809353 & 1.235052 & 0.926614 & 1.804207 & 0.277238 & -0.851250 \\
99 & -0.802192 & 1.268369 & 1.014724 & 1.784694 & 0.425625 & -0.772235 \\
\hline
\end{tabular}

can be observed that they are approximately the same within two places of decimals, with some to three places of decimals.

Figure 4(a) shows that power law decreases with the increase in RHs.

From Table 5(a), it can be observe that the correlations decrease with the increase in RHs, but increases with the increase in the power of the polynomials.

From Figure 4(b) it can be observed that power law is not obeyed.

Table 5(b) shows poor correlation in the linear part, but good correlations at second and third order polynomials, and the correlations increase with the increase in order of the polynomials and RHs.

Comparing Figures 4(c) and (a), it can be observed that they are similar.

From Table 5(c), it can be seen that the correlations decrease with the increase in RHs, but increases with the increase in the power of the polynomials.

From Table 5(d), from the linear part it can be seen that Equation (1) underestimated Equation (7) at $0 \%$ to $70 \% \mathrm{RH}$, and overestimated it at $90 \%$ to $99 \% \mathrm{RH}$. At the quadratic part Equations (1) and (9) are equal within two places of decimals, but at RHs $95 \%$ to $99 \%$ Equation (1) underestimated Equation (9). At the cubic part, Equations (1) and (12) are the same within two places of decimals except at $98 \%$ and $99 \%$ where Equation (1) underestimated Equation (2).

Figure 4(d) shows that power law is not obeyed.

From Table 5(e) it can be seen from the linear part that there is a poor correlation between single scattering albedo and wavelength, though as the power of the polynomials increase the relation also improves.

Comparing Tables 5(e) and (f) it can be observed that in the linear part only the values at $80 \%, 95 \%$ and $99 \%$ agree to three places of decimals. This can be attributed to the poor correlations at Table 5(e). From the quadratic and cubic some coefficients agree to two places while some to three places of decimals.

Figure 4(e) in the inverse of Figure 4(d).

Table 5(g) shows poor correlations in the linear part. There are good correlations at quadratic and cubic polynomials, though poor correlation can be observed at $99 \%$ RH throughout. 


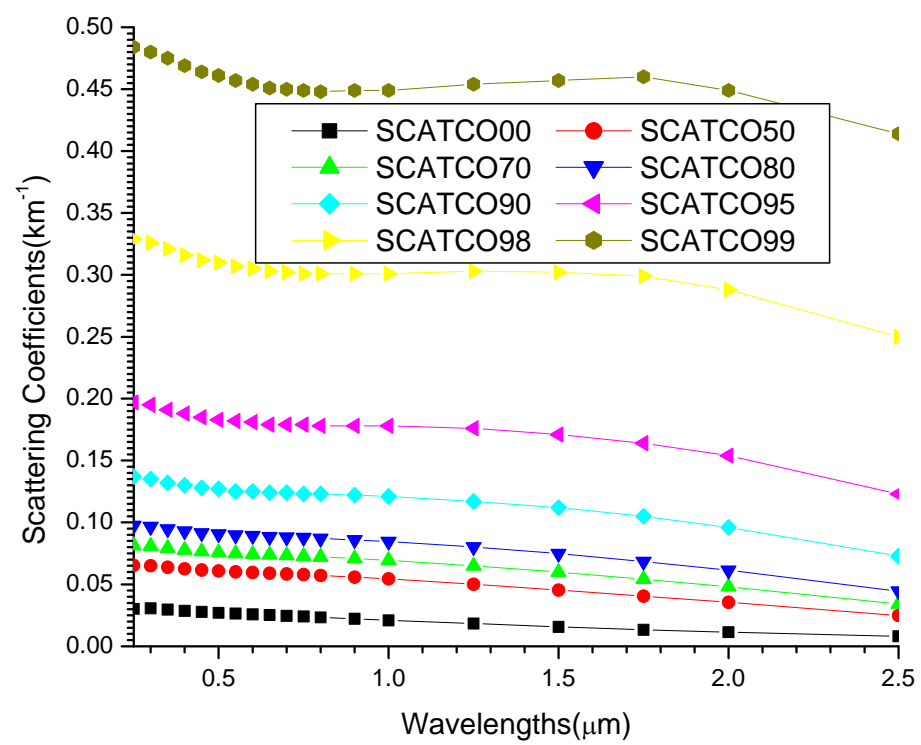

Figure 4(a). A graph of scattering coefficients against wavelength for maritime clean at RHs $0 \%, 50 \%, 70 \%, 80 \%, 90 \%, 95 \%$, $98 \%$ and $99 \%$.

Table 5(a). The results of the Angstrom coefficients of scattering coefficients using Equations (5), (6) and (10) for maritime clean model at the respective relative humidities using regression analysis with SPSS16.0.

\begin{tabular}{cccccccccc}
\hline $\mathrm{RH}$ & \multicolumn{2}{c}{ Linear Equation (5) } & \multicolumn{3}{c}{ Quadratic Equation (6) } & \multicolumn{4}{c}{ Cubic Equation (10) } \\
\hline$(\%)$ & $\mathrm{R}^{2}$ & $\alpha$ & $\mathrm{R}^{2}$ & $\alpha_{1}$ & $\alpha_{2}$ & $\mathrm{R}^{2}$ & $\alpha_{1}$ & $\alpha_{2}$ & $\alpha_{3}$ \\
\hline 0 & 0.8698 & 0.5242 & 0.9906 & -0.6572 & -0.2896 & 0.9989 & -0.5721 & -0.3867 & -0.1273 \\
50 & 0.7704 & 0.3328 & 0.9539 & -0.4434 & -0.2408 & 0.9946 & -0.3163 & -0.3858 & -0.1901 \\
70 & 0.7525 & 0.2866 & 0.9366 & -0.3832 & -0.2102 & 0.9915 & -0.2546 & -0.3568 & -0.1922 \\
80 & 0.7397 & 0.2515 & 0.9199 & -0.3360 & -0.1841 & 0.9883 & -0.2091 & -0.3289 & -0.1899 \\
90 & 0.7244 & 0.1908 & 0.8796 & -0.2510 & -0.1310 & 0.9784 & -0.1340 & -0.2645 & -0.1750 \\
95 & 0.7060 & 0.1340 & 0.8192 & -0.1706 & -0.0796 & 0.9554 & -0.0728 & -0.1911 & -0.1462 \\
98 & 0.6908 & 0.0730 & 0.7125 & -0.0818 & -0.0192 & 0.8845 & -0.0213 & -0.0882 & -0.0905 \\
99 & 0.6084 & 0.0401 & 0.6268 & -0.0353 & 0.0103 & 0.7891 & -9.5139 & -0.0289 & -0.0514 \\
\hline
\end{tabular}

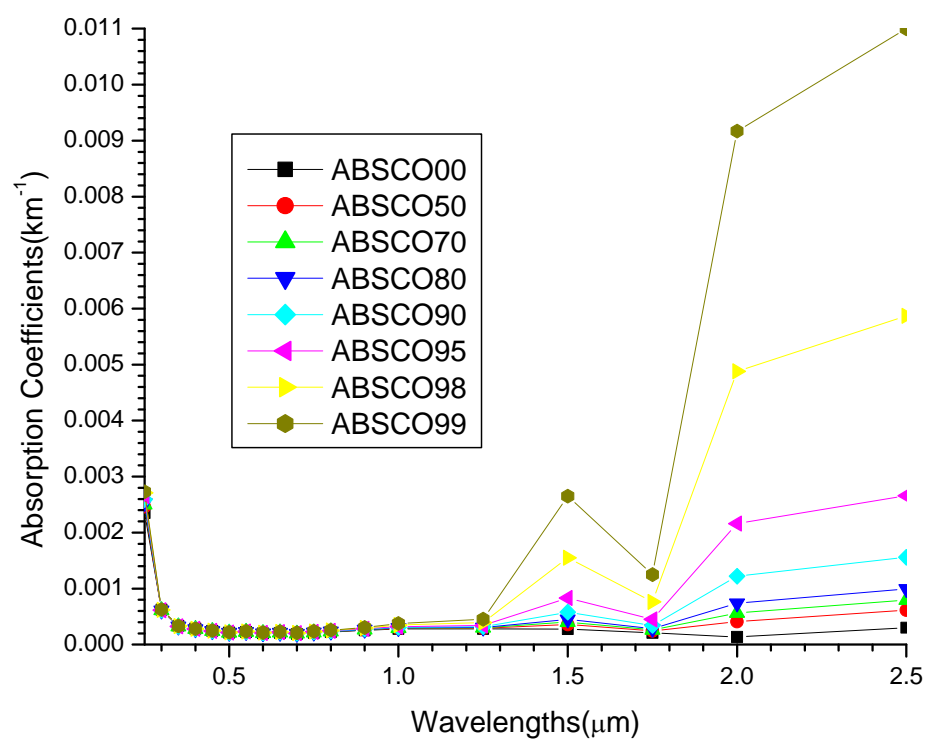

Figure 4(b). A graph of absorption coefficients against wavelength for maritime clean at RHs $\mathbf{0 \%}, \mathbf{5 0} \%, \mathbf{7 0} \%, \mathbf{8 0} \%, \mathbf{9 0} \%$, 95\%, $98 \%$ and $99 \%$. 
Table 5(b). The results of the Angstrom coefficients of absorption coefficients using Equations (5), (6) and (10) for maritime clean model at the respective relative humidities using regression analysis with SPSS16.0.

\begin{tabular}{ccccccccccc}
\hline RH & \multicolumn{2}{c}{ Linear } & \multicolumn{3}{c}{ Quadratic } & \multicolumn{3}{c}{ Cubic } \\
\hline$(\%)$ & $\mathrm{R}^{2}$ & $\alpha$ & $\mathrm{R}^{2}$ & $\alpha_{1}$ & $\alpha_{2}$ & $\mathrm{R}^{2}$ & $\alpha_{1}$ & $\alpha_{2}$ & $\alpha_{3}$ \\
\hline 0 & 0.2846 & 0.4908 & 0.6576 & -0.1081 & 0.8328 & 0.8516 & 0.5647 & 0.0652 & -1.0063 \\
50 & 0.0391 & 0.1833 & 0.7554 & 0.3512 & 1.1634 & 0.8894 & 0.9147 & 0.5204 & -0.8429 \\
70 & 0.0067 & 0.0799 & 0.7822 & 0.5037 & 1.2703 & 0.8899 & 1.0339 & 0.6653 & -0.7930 \\
80 & 0.0001 & -0.0106 & 0.8041 & 0.6368 & 1.3629 & 0.8903 & 1.1369 & 0.7923 & -0.7480 \\
90 & 0.0277 & -0.1927 & 0.8392 & 0.9028 & 1.5455 & 0.8943 & 1.3540 & 1.0307 & -0.6748 \\
95 & 0.0961 & -0.4180 & 0.8720 & 1.2267 & 1.7603 & 0.9050 & 1.6339 & 1.2957 & -0.6090 \\
98 & 0.2118 & -0.7747 & 0.9045 & 1.7287 & 2.0765 & 0.9230 & 2.1088 & 1.6428 & -0.5686 \\
99 & 0.2933 & -1.0722 & 0.9205 & 2.1399 & 2.3242 & 0.9338 & 2.5189 & 1.8917 & -0.5669 \\
\hline
\end{tabular}

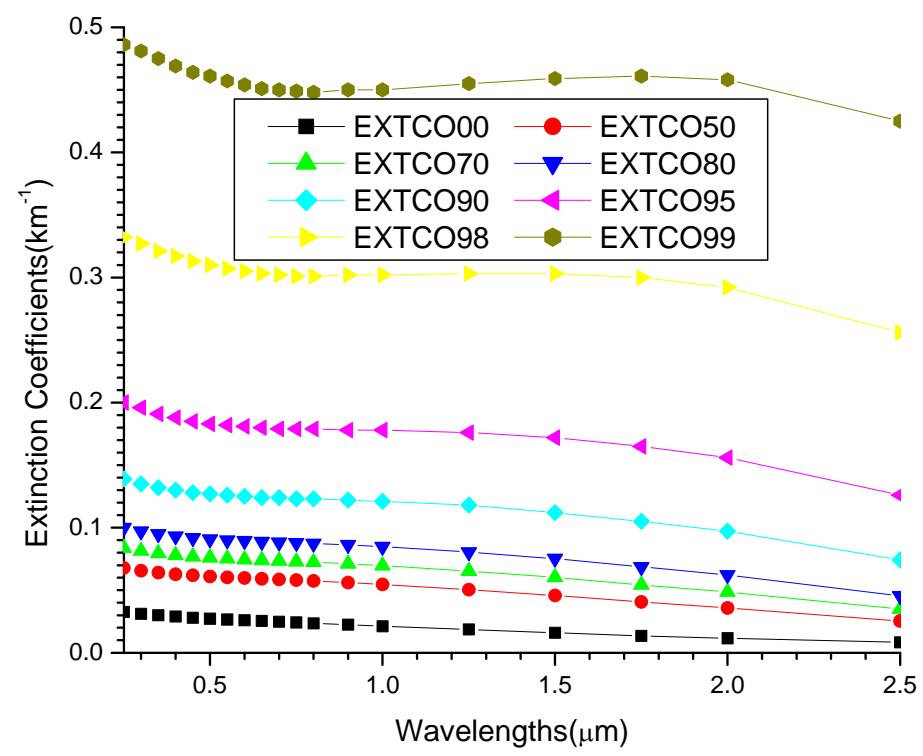

Figure 4(c). A graph of extinction coefficients against wavelength for maritime clean at RHs $0 \%, 50 \%, 70 \%, 80 \%, 90 \%, 95 \%$, $98 \%$ and $99 \%$.

Table 5(c). The results of the Angstrom coefficients of extinction coefficients using Equations (5), (6) and (10) for maritime clean model at the respective relative humidities using regression analysis with SPSS16.0.

\begin{tabular}{ccccccccccc}
\hline $\mathrm{RH}$ & \multicolumn{2}{c}{ Linear } & \multicolumn{3}{c}{ Quadratic } & \multicolumn{3}{c}{ Cubic } \\
\hline$(\%)$ & $\mathrm{R}^{2}$ & $\alpha$ & $\mathrm{R}^{2}$ & $\alpha_{1}$ & $\alpha_{2}$ & $\mathrm{R}^{2}$ & $\alpha_{1}$ & $\alpha_{2}$ & $\alpha_{3}$ \\
\hline 0 & 0.8883 & 0.5272 & 0.9880 & -0.6475 & -0.2618 & 0.9998 & -0.5464 & -0.3772 & -0.1512 \\
50 & 0.7887 & 0.3333 & 0.9515 & -0.4365 & -0.2245 & 0.9966 & -0.3041 & -0.3755 & -0.1980 \\
70 & 0.7704 & 0.2863 & 0.9352 & -0.3765 & -0.1963 & 0.9942 & -0.2449 & -0.3464 & -0.1968 \\
80 & 0.7571 & 0.2501 & 0.9180 & -0.3286 & -0.1709 & 0.9910 & -0.1997 & -0.3180 & -0.1928 \\
90 & 0.7395 & 0.1877 & 0.8798 & -0.2434 & -0.1212 & 0.9817 & -0.1277 & -0.2533 & -0.1731 \\
95 & 0.7260 & 0.1300 & 0.8153 & -0.1611 & -0.0676 & 0.9608 & -0.0644 & -0.1778 & -0.1445 \\
98 & 0.7056 & 0.0686 & 0.7108 & -0.0726 & -0.0088 & 0.8872 & -0.0157 & -0.0737 & -0.0852 \\
99 & 0.5279 & 0.0332 & 0.6218 & -0.0236 & 0.0207 & 0.7764 & 0.0062 & -0.0133 & -0.0446 \\
\hline
\end{tabular}


Table 5(d). The results of the Angstrom coefficients of extinction coefficients using Equations (1), (7), (9) and (12) for maritime clean model at the respective relative humidities using regression analysis with SPSS16.0.

\begin{tabular}{ccccccc}
\hline RH & \multicolumn{2}{c}{ Linear } & \multicolumn{2}{c}{ Quadratic } & \multicolumn{2}{c}{ Cubic } \\
\hline$(\%)$ & Equation (7) & Equation (1) & Equation $(9)$ & Equation $(1)$ & Equation $(12)$ & Equation $(1)$ \\
\hline & $\alpha$ & $\alpha$ & $\alpha_{1}(\lambda)$ & $\alpha_{1}(\lambda)$ & $\alpha_{2}(\lambda)$ & $\alpha_{2}(\lambda)$ \\
\hline 0 & 0.527214 & 0.508211 & 0.488677 & 0.486895 & 0.540925 & 0.548030 \\
50 & 0.333319 & 0.328780 & 0.300276 & 0.298072 & 0.368672 & 0.371082 \\
70 & 0.286304 & 0.284118 & 0.257418 & 0.254929 & 0.325406 & 0.327440 \\
80 & 0.250051 & 0.250105 & 0.224894 & 0.222541 & 0.291486 & 0.293302 \\
90 & 0.187726 & 0.190850 & 0.169883 & 0.167824 & 0.229678 & 0.232161 \\
95 & 0.130000 & 0.135132 & 0.120053 & 0.115855 & 0.169988 & 0.169726 \\
98 & 0.068600 & 0.075620 & 0.067313 & 0.059593 & 0.096742 & 0.094223 \\
99 & 0.033156 & 0.043773 & 0.036207 & 0.026458 & 0.051601 & 0.048180 \\
\hline
\end{tabular}

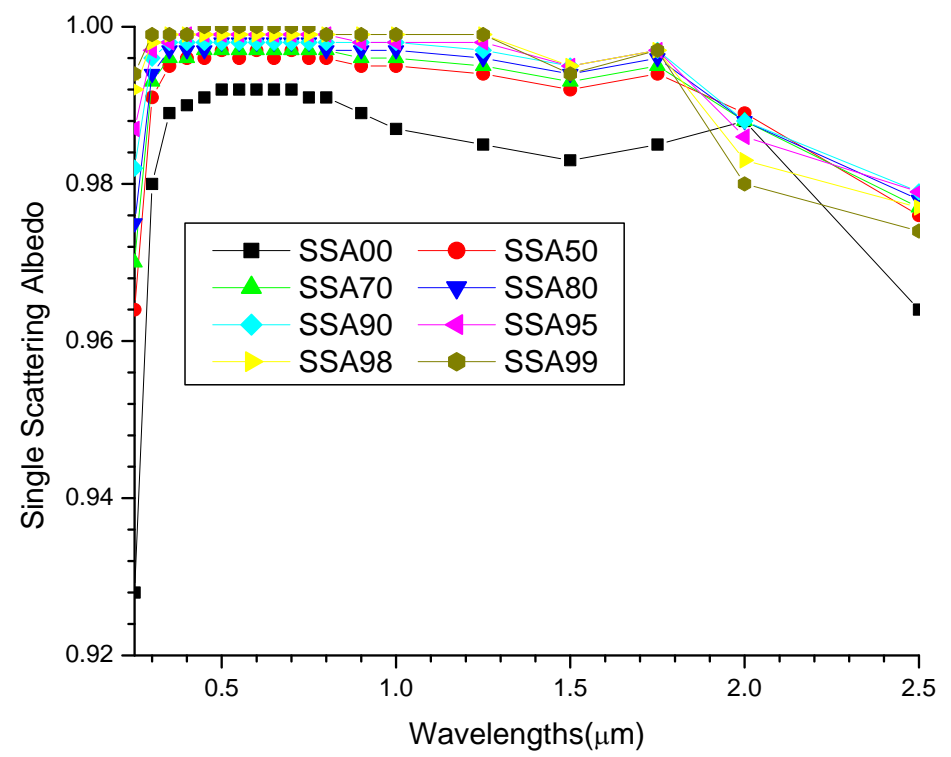

Figure 4(d). A graph of single scattering albedo against wavelength for maritime clean at RHs $0 \%, 50 \%, 70 \%, 80 \%, 90 \%$, $\mathbf{9 5 \%}, \mathbf{9 8 \%}$ and $99 \%$.

Table 5(e). The results of the Angstrom coefficients of single scattering albedo using Equations (4), (5) and (6) for maritime clean model at the respective relative humidities using regression analysis with SPSS16.0.

\begin{tabular}{cccccccccc}
\hline $\mathrm{RH}$ & \multicolumn{2}{c}{ Linear } & \multicolumn{3}{c}{ Quadratic } & \multicolumn{3}{c}{ Cubic } \\
\hline$(\%)$ & $\mathrm{R}^{2}$ & $\alpha$ & $\mathrm{R}^{2}$ & $\alpha_{1}$ & $\alpha_{2}$ & $\mathrm{R}^{2}$ & $\alpha_{1}$ & $\alpha_{2}$ & $\alpha_{3}$ \\
\hline 0 & 0.0260 & -0.0039 & 0.5943 & -0.0085 & -0.0271 & 0.7281 & -0.0233 & -0.0103 & 0.0220 \\
50 & 0.0004 & 0.0003 & 0.6761 & -0.0071 & -0.0159 & 0.7296 & -0.0121 & -0.0102 & 0.0075 \\
70 & 0.0035 & 0.0007 & 0.7124 & -0.0073 & -0.0144 & 0.7396 & -0.0105 & -0.0108 & 0.0047 \\
80 & 0.0165 & 0.0013 & 0.7493 & -0.0074 & -0.0133 & 0.7614 & -0.0093 & -0.0111 & 0.0029 \\
90 & 0.0684 & 0.0023 & 0.7647 & -0.0074 & -0.0110 & 0.7650 & -0.0071 & -0.0113 & -0.0004 \\
95 & 0.1733 & 0.0036 & 0.8283 & -0.0085 & -0.0105 & 0.8358 & -0.0072 & -0.0119 & -0.0019 \\
98 & 0.2977 & 0.0052 & 0.8145 & -0.0098 & -0.0101 & 0.8683 & -0.0062 & -0.0143 & -0.0055 \\
99 & 0.3691 & 0.0068 & 0.8278 & -0.0119 & -0.0112 & 0.8850 & -0.0075 & -0.0162 & -0.0066 \\
\hline
\end{tabular}


Table 5(f). The results of the Angstrom coefficients of single scattering albedo using equations (2) for maritime clean model at the respective relative humidities.

\begin{tabular}{|c|c|c|c|c|c|c|}
\hline \multirow{2}{*}{$\frac{\mathrm{RH}}{(\%)}$} & \multirow{2}{*}{$\begin{array}{c}\text { Linear } \\
\alpha\end{array}$} & \multicolumn{2}{|c|}{ Quadratic } & \multicolumn{3}{|c|}{ Cubic } \\
\hline & & $\alpha_{1}$ & $\alpha_{2}$ & $\alpha_{1}$ & $\alpha_{2}$ & $\alpha_{3}$ \\
\hline 0 & -0.003031 & -0.009733 & -0.027784 & -0.025744 & -0.009515 & 0.023948 \\
\hline 50 & -0.000519 & -0.006946 & -0.016250 & -0.012226 & -0.010226 & 0.007896 \\
\hline 70 & 0.000302 & -0.006685 & -0.013895 & -0.009724 & -0.010429 & 0.004544 \\
\hline 90 & 0.003115 & -0.007588 & -0.009736 & -0.006272 & -0.011237 & -0.001968 \\
\hline 95 & 0.003996 & -0.009503 & -0.011988 & -0.008400 & -0.013246 & -0.001649 \\
\hline 98 & 0.004397 & -0.009176 & -0.010401 & -0.005641 & -0.014434 & -0.005286 \\
\hline 99 & 0.006924 & -0.011701 & -0.010399 & -0.007112 & -0.015636 & -0.006865 \\
\hline
\end{tabular}

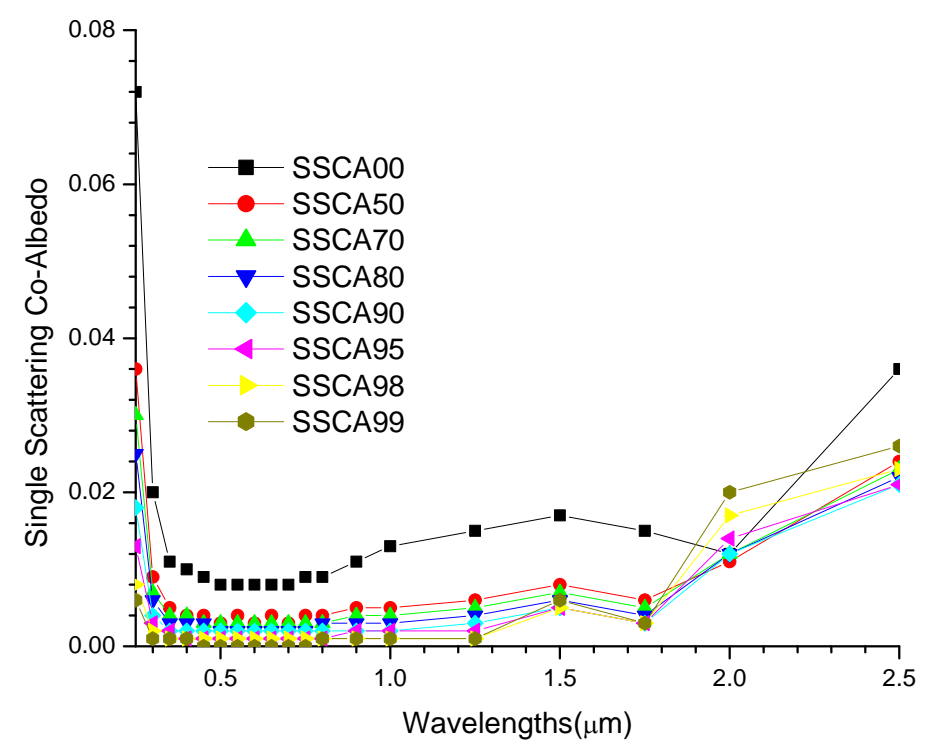

Figure 4(e). A graph of single scattering co-albedo against wavelength for maritime clean at RHs $0 \%, 50 \%, 70 \%, 80 \%, 90 \%$, $95 \%, 98 \%$ and $99 \%$.

Table 5(g). The results of the Angstrom coefficients of single scattering co-albedo using Equations (5), (6) and (10) for maritime clean model at the respective relative humidities using regression analysis with SPSS16.0.

\begin{tabular}{ccccccccccc}
\hline RH & \multicolumn{2}{c}{ Linear Equation (5) } & \multicolumn{3}{c}{ Quadratic Equation (6) } & \multicolumn{5}{c}{ Cubic Equation (10) } \\
\hline$(\%)$ & $\mathrm{R}^{2}$ & $\alpha$ & $\mathrm{R}^{2}$ & $\alpha_{1}$ & $\alpha_{2}$ & $\mathrm{R}^{2}$ & $\alpha_{1}$ & $\alpha_{2}$ & $\alpha_{3}$ \\
\hline 0 & 0.0012 & -0.0302 & 0.7001 & 0.5346 & 1.0978 & 0.8425 & 1.0898 & 0.4644 & -0.8304 \\
50 & 0.0257 & -0.1670 & 0.8072 & 0.7943 & 1.3654 & 0.8798 & 1.2605 & 0.8335 & -0.6973 \\
70 & 0.0417 & -0.2199 & 0.8484 & 0.8785 & 1.4336 & 0.8947 & 1.2634 & 0.9944 & -0.5757 \\
80 & 0.0575 & -0.2906 & 0.8604 & 1.0301 & 1.6097 & 0.9018 & 1.4397 & 1.1424 & -0.6126 \\
90 & 0.0964 & -0.3763 & 0.8397 & 1.0881 & 1.5493 & 0.8530 & 1.3202 & 1.2845 & -0.3472 \\
95 & 0.1709 & -0.6389 & 0.8835 & 1.5274 & 1.9340 & 0.9221 & 2.0316 & 1.3586 & -0.7542 \\
98 & 0.2308 & -0.7704 & 0.8858 & 1.6544 & 1.9240 & 0.8870 & 1.7469 & 1.8184 & -0.1384 \\
99 & 0.1270 & -0.5957 & 0.2027 & 0.9088 & 0.6816 & 0.3329 & -0.0929 & 1.8245 & 1.4982 \\
\hline
\end{tabular}

Comparing Tables 5(g) and (h) it can be seen that from the linear part they are different, and this can be attributed to the poor correlations in 5(g). From the quadratic and cubic, the coefficients from Tables $\mathbf{5}(\mathrm{g})$ and (h) 
Table 5(h). The results of the Angstrom coefficients of single scattering co-albedo using Equation (3) for maritime clean model at the respective relative humidities.

\begin{tabular}{|c|c|c|c|c|c|c|}
\hline \multirow{2}{*}{$\begin{array}{l}\mathrm{RH} \\
(\%) \\
\end{array}$} & \multirow{2}{*}{$\begin{array}{c}\text { Linear } \\
\qquad \alpha\end{array}$} & \multicolumn{2}{|c|}{ Quadratic } & \multicolumn{3}{|c|}{ Cubic } \\
\hline & & $\alpha_{1}$ & $\alpha_{2}$ & $\alpha_{1}$ & $\alpha_{2}$ & $\alpha_{3}$ \\
\hline 0 & -0.036462 & 0.539358 & 1.094649 & -0.018294 & 0.312034 & 1.157534 \\
\hline 50 & -0.150011 & 0.787625 & 1.387888 & -0.610640 & -0.144866 & 1.040860 \\
\hline 70 & -0.206397 & 0.880150 & 1.466550 & -0.789011 & -0.318965 & 0.989806 \\
\hline 80 & -0.260667 & 0.965345 & 1.533866 & -0.937193 & -0.474357 & 0.940760 \\
\hline 90 & -0.380442 & 1.146174 & 1.666761 & -1.226255 & -0.777471 & 0.847912 \\
\hline 95 & -0.548017 & 1.387765 & 1.827872 & -1.569516 & -1.117854 & 0.753569 \\
\hline 98 & -0.843281 & 1.801288 & 2.085286 & -2.093174 & -1.569053 & 0.653780 \\
\hline 99 & -1.105303 & 2.163529 & 2.303430 & -2.525064 & -1.878473 & 0.611415 \\
\hline
\end{tabular}

are almost the same, but to only one place of decimals.

\section{Conclusions}

From all the tables and graphs obtained, it can be seen that it is only urban aerosols that scattering, absorption and extinction coefficients that satisfy power laws excellently at this spectral range and can be seen that it is the only aerosols that show very good relations between the estimated Equations (1)-(3) and the linear Equation (5). Linear models are considered most important, because they are the values that are obtainable from remote sensing and ground truthing instruments.

Another observation made is that Equations (1) and (2) are sufficient. This is because the information that can be obtained from equation is almost the same as that of Equation (3).

Additional important observation made from the various graphs is that, at the spectral range of 0.4 to 1.5 power laws are obeyed by all the aerosols. Therefore, since $99 \%$ of sun's radiation falls between 0.2 - $5.6 \mu \mathrm{m}$; and $80 \%$ falls between $0.4-1.5 \mu \mathrm{m}$ (visible and near infrared) and the atmosphere is quite transparent to incoming solar radiation with the maximum radiation at $0.48 \mu \mathrm{m}$ (visible) and in the study of the earth's surface, most of the remote sensing instruments are designed to operate within solar spectral window $(0.4-0.7 \mu \mathrm{m})$ and near infrared $(0.7-1.5 \mu \mathrm{m})$, where cloudless atmosphere will transmit sufficient radiation for detection, which also shows that these formulas can be useful in remote sensing.

\section{REFERENCES}

[1] A. Angstrom, "On the Atmospheric Transmission of Sun Radiation and on Dust in the Air," Geografiska Annaler, Vol. 11, 1929, pp. 156-166. http://dx.doi.org/10.2307/519399

[2] A. Angstrom, "On the Atmospheric Transmission of Sun Radiation II," Geografiska Annaler, Vol. 12, 1930, pp. 130-159. http://dx.doi.org/10.2307/519561
[3] A. Angstrom, "Techniques of Determining the Turbidity of the Atmosphere," Tellus, Vol. 13, No. 2, 1961, pp. 214-223. http://dx.doi.org/10.1111/j.2153-3490.1961.tb00078.x

[4] A. Angstrom, "The Parameters of Atmospheric Turbidity," Tellus, Vol. 16, No. 1, 1964, pp. 64-75. http://dx.doi.org/10.1111/j.2153-3490.1964.tb00144.x

[5] P. B. Russell, R. W. Bergstrom, Y. Shinozuka, A. D. Clarke, P. F. De-Carlo, J. L. Jimenez, J. M. Livingston, J. Redemann, O. Dubovik and A. Strawa, "Absorption Angstrom Exponent in AERONET and Related Data as an Indicator of Aerosol Composition," Atmospheric Chemistry and Physics, Vol. 10, 2010, pp. 1155-1169.

http://dx.doi.org/10.5194/acp-10-1155-2010

[6] E. V. Fischer, D. A. Jaffe, N. A. Marley, J. S. Gaffney and A. Marchany-Rivera, "Optical Properties of Aged Asian Aerosols Observed over the US Pacific Northwest," Journal of Geophysical Research, Vol. 115, No. D20, 2010. http://dx.doi.org/10.1029/2010JD013943

[7] A. Virkkula, N. C. Ahlquist, D. S. Covert, W. P. Arnott, P. J. Sheridan, P. K. Quinn and D. J. Coffman, "Modification, Calibration and a Field Test of an Instrument for Measuring Light Absorption by Particles," Aerosol Science and Technology, Vol. 39, No. 1, 2005, pp. 68-83.

[8] B. A. Flowers, M. K. Dubey, C. Mazzoleni, E. A. Stone, J. J. Schauer, S.-W. Kim and S. C. Yoon, "Optical-Chemical-Microphysical Relationships and Closure Studies for Mixed Car-Bonaceous Aerosols Observed at Jeju Island; 3-Laser Photoa-Coustic Spectrometer, Particle Sizing, and Filter Analysis," Atmospheric Chemistry and Physics, Vol. 10, 2010, pp. 10387-10398.

http://dx.doi.org/10.5194/acp-10-10387-2010

[9] N. O’Neill and A. Royer, "Extraction of Bimodal Aerosol-Size Distribution Radii from Spectral and Angular Slope (Angstrom) Coefficients," Applied Optics, Vol. 32, No. 9, 1993, pp. 1642-1645. http://dx.doi.org/10.1364/AO.32.001642

[10] M. K. Latha and K. V. S. Badarinath, "Factors Influencing Aerosol Characteristics over Urban Environment," Environmental Monitoring and Assessment, Vol. 104, No. $1-3,2005$, pp. 269-280. http://dx.doi.org/10.1007/s10661-005-1615-7

[11] J. S. Reid, T. F. Eck, S. A. Christopher, P. V. Hobbs and B. Holben, "Use of the Angstrom Exponent to Estimate 
the Variability of Optical and Physical Properties of Aging Smoke Particles in Brazil," Journal of Geophysical Research, Vol. 104, No. D22, 1999, pp. 27473-27489. http://dx.doi.org/10.1029/1999JD900833

[12] T. F. Eck, B. N. Holben, D. E. Ward, M. M. Mukelabai, O. Dubovik, A. Smirnov, J. S. Schafer, N. C. Hsu, S. J. Piketh, A. Queface, J. Le Roux, R. J. Swap and I. Slutsker, "Variability of Biomass Burning Aerosol Optical Characteristics in Southern Africa during the SAFARI 2000 Dry Season Campaign and a Comparison of Single Scattering Albedo Estimates from Radiometric Measurements," Journal of Geophysical Research, Vol. 108 No. D13, 2003, p. 8477.

[13] T. F. Eck, B. N. Holben, J. S. Reid, O. Dubovic, A. Smirnov, N. T. O'Neill, I. Slutsker and S. Kinne, "Wavelength Dependence of the Optical Depth of Biomass Burning, Urban, and Desert Dust Aerosols," Journal of Geophysical Research, Vol. 104, No. D24, 1999, pp. 31333-31349. http://dx.doi.org/10.1029/1999JD900923

[14] A. Smirnov, A. Royer, N. T. O’Neill and A. Tarussov, “A Study of the Link between Synoptic Air Mass Type and Atmospheric Optical Parameters," Journal of Geophysical Research, Vol. 99, No. D10, 1994, pp. 20967-20982. http://dx.doi.org/10.1029/94JD01719

[15] N. C. Hsu, S. C. Tsay, M. D. King and J. R. Herman, "Deep-Blue retrievals of Asian aerosol properties during ACE-Asia," IEEE Transactions on Geoscience and Remote Sensing, Vol. 44, No. 11, 2006, pp. 3180-3195. http://dx.doi.org/10.1109/TGRS.2006.879540

[16] H. Moosmuller, R. K. Chakrabarty and W. P. Arnott, "Aerosol Light Absorption and Its Measurement: A Review," Journal of Quantitative Spectroscopy and Radiative Transfer, Vol. 110, NO. 11, 2009, pp. 844-878. http://dx.doi.org/10.1016/j.jqsrt.2009.02.035

[17] H. Moosmuller and R. K. Chakrabarty, "Technical Note: Simple Analytical Relationships between Angstrom Coefficients of Aerosol Extinction, Scattering, Absorption, and Single Scattering Albedo," Atmospheric Chemistry and Physics, Vol. 11, 2011, pp. 10677-10680. http://dx.doi.org/10.5194/acp-11-10677-2011

[18] K. Lewis, W. P. Arnott, H. Moosmuller and C. E. Wold, "Strong Spectral Variation of Biomass Smoke Light Absorption and Single Scattering Albedo Observed with a Novel Dual-Wavelength Photoacoustic Instrument," Journal of Geophysical Research, Vol. 113, No. D16, 2008. http://dx.doi.org/10.1029/2007JD009699

[19] O. Dubovik, B. N. Holben, Y. J. Kaufman, M. Yamasoe, A. Smirnov, D. Tanre and I. Slutsker, "Single-Scattering Albedo of Smoke Retrieved from the Sky Radiance and Solar Transmittance Measured from Ground," Journal of Geophysical Research, Vol. 103, No. D24, 1998, pp. 31901-31923. http://dx.doi.org/10.1029/98JD02276

[20] O. Dubovik and M. D. King, "A Flexible Inversion Algorithm for Retrieval of Aerosol Optical Properties from Sun and Sky Radiance Measurements," Journal of Geophysical Research, Vol. 105, No. D16, 2000, pp. 2067320696. http://dx.doi.org/10.1029/2000JD900282

[21] M. I. Mishchenko, B. Cairns, G. Kopp, C. F. Schueler, B. A. Fafaul, J. E. Hansen, R. J. Hooker, T. Itchkawich, H. B. Maring and L. D. Travis, "Accurate Monitoring of Ter- restrial Aerosols and Total Solar Irradiance-Introducing the Glory Mission," Bulletin of the American Meteorological Society, Vol. 88, No. 5, 2007, pp. 677-691. http://dx.doi.org/10.1175/BAMS-88-5-677

[22] L. Zhu, J. V. Martins and L. A. Remer, "Biomass Burning Aerosol Absorption Measurements with MODIS Using the Critical Reflectance Method," Journal of Geophysical Research, Vol. 116, No. D7, 2011. http://dx.doi.org/10.1029/2010JD015187

[23] A. Sanchez, T. F. Smith and W. F. Krajewski, "A ThreeDimensional Atmospheric Radiative Transfer Model Based on the Discrete-Ordinates Method," Atmospheric Research, Vol. 33, No. 1-4, 1994, pp. 283-308. http://dx.doi.org/10.1016/0169-8095(94)90024-8

[24] Z. Li, P. Goloub, C. Devaux, X. Gu, Y. Qiao, F. Zhao and H. Chen, "Aerosol Polarized Phase Function and SingleScattering Albedo Retrieved from Ground-Based Measurements," Atmospheric Research, Vol. 71, No. 4, 2004, pp. 233-241. http://dx.doi.org/10.1016/j.atmosres.2004.06.001

[25] K. N. Liou and Y. Takano, "Light Scattering by Nonspherical Particles: Remote Sensing and Climatic Implications," Atmospheric Research, Vol. 31, No. 4, 1994, pp. 271-298. http://dx.doi.org/10.1016/0169-8095(94)90004-3

[26] A. Kylling, A.F. Bais, M. Blumthaler, J. Shreder and C. S. Zerefos, "UV Irradiances during the PAUR Campaign: Comparison between Measurement and Model Simulations," Journal of Geophysical Research, Vol. 103 No. D20, 1998, pp. 26051-26060.

[27] G. L. Schuster, O. Dubovik and B. N. Holben, "Angstrom Exponent and Bimodal Aerosol Size Distributions," Journal of Geophysical Research, Vol. 111, No. D7, 2006. http://dx.doi.org/10.1029/2005JD006328

[28] M. Hess, P. Koepke and I. Schult, "Optical Properties of Aerosols and Clouds: The Software Package OPAC," Bulletin of the American Meteorological Society, Vol. 79, No. 5, 1998, pp. 831-844.

[29] K. N. Liou, "An Introduction to Atmospheric Radiation," 2nd Edition, Academic Press, San Diego, 2002, p. 583.

[30] M. D. King and D. M. Byrne, "A Method for Inferring Total Ozone Content from Spectral Variation of Total Optical Depth Obtained with a Solar Radiometer," Journal of the Atmospheric Sciences, Vol. 33, No. 11, 1976, pp. 2242-2251.

http://dx.doi.org/10.1175/1520-0469(1976)033<2242:AM FITO $>2.0 . \mathrm{CO} ; 2$

[31] T. F. Eck, B. N. Holben, O. Dubovic, A. Smirnov, I. Slutsker, J. M. Lobert and V. Ramanathan, "Column-Integrated Aerosol Optical Properties over the Maldives During the Northeast Mon-Soon for 1998-2000," Journal of Geophysical Research, Vol. 106, No. D22, 2001, pp. 28555-28566.

[32] T. F. Eck, B. N. Holben, D. E. Ward, O. Dubovic, J. S. Reid, A. Smirnov, M. M. Mukelabai, N. C. Hsu, N. T. O' Neil and I. Slutsker, "Characterization of the Optical Properties of Biomass Burning Aerosols in Zambia during the 1997 ZIBBEE Field Campaign," Journal of Geophysical Research, Vol. 106, No. D4, 2001, pp. 3425- 
3448. http://dx.doi.org/10.1029/2000JD900555

[33] Y. J. Kaufman, “Aerosol Optical Thickness and Atmospheric Path Radiance," Journal of Geophysical Research, Vol. 98, No. D2, 1993, pp. 2677-2992. http://dx.doi.org/10.1029/92JD02427

[34] N. T. O’Neill, T. F. Eck, B. N. Holben, A. Smirnov, O. Dubovik and A. Royer, "Bimodal Size Distribution Influences on the Variation of Angstrom Derivatives in Spectral and Optical Depth Space," Journal of Geophysical Research, Vol. 106, No. D9, 2001, pp. 9787-9806. http://dx.doi.org/10.1029/2000JD900245

[35] N. T. O’Neill, T. F. Eck, A. Smirnov, B. N. Holben and S. Thulasiraman, "Spectral Discrimination of Coarse and Fine Mode Optical Depth," Journal of Geophysical Research, Vol. 198, No. D17, 2003, p. 4559.

[36] D. G. Kaskaoutis and H. D. Kambezidis, "Investigation into the Wavelength Dependence of the Aerosol Optical Depth in the Athens Area," Journal of the Royal Meteorological Society, Vol. 132, No. 620, 2006, pp. 2217-2234. http://dx.doi.org/10.1256/qi.05.183

[37] B. Schmid, D. A. Hegg, J. Wang, D. Bates, J. Redemann, P. B. Russell, J. M. Livingston, H. H. Jonsson, E. J. Welton, J. H. Seinfeld, R. C. Flagan, D. S. Covert, O. Dubovik, A. Jefferson, "Column Closure Studies of Lower Tropospheric Aerosol and Water Vapor During ACEAsia Using Airborne Sun Photometer and Airborne in Situ and Ship-Based Lidar Measurements," Journal of Geophysical Research, Vol. 108 No. D23, 2003, p. 8656. http://dx.doi.org/10.1029/2002JD003361
[38] J. A. Martinez-Lozano, M. P. Utrillas, F. Tena, Pedros, R., J. Canada, J. V. Bosca and J. Lorente, "Aerosol Optical Characteristics from Summer Campaign in an Urban Coastal Mediterranean Area," IEEE Transactions on Geoscience and Remote Sensing, Vol. 39, No. 7, 2001, pp. 1573-1585. http://dx.doi.org/10.1109/36.934089

[39] D. G. Kaskaoutis, H. D. Kambezidis, N. Hatzianastassiou, P. G. Kosmopoulos and K. V. S. Badarinath, "Aerosol Climatology: Dependence of the Angstrom Exponent on Wavelength over Four AERONET Sites," Atmospheric Chemistry and Physics, Vol. 7, 2007, pp. 7347-7397. http://dx.doi.org/10.5194/acpd-7-7347-2007

[40] D. G. Kaskaoutis, H. D. Kambezidis, , N. Hatzianastassiou, P. G. Kosmopoulos and K. V. S. Badarinath, "Aerosol Climatology: On the Discrimination of Aerosol Types over Four AERONET Sites," Atmospheric Chemistry and Physics Discussion, Vol. 7, No. 3, 2007, pp. 6357-6411.

[41] J. W. Fitzgerald, “Approximation Formulas for the Equilibrium Size of an Aerosol Particle as a Function of Its Dry Size and Composition and Ambient Relative Humidity," Journal of Applied Meteorology, Vol. 14, No. 6, 1975, pp. 1044-1049. http://dx.doi.org/10.1175/1520-0450(1975)014<1044:AF FTES $>2.0 . \mathrm{CO} ; 2$

[42] I. N. Tang, "Chemical and Size Effects of Hygroscopic Aerosols on Light Scattering Coefficients," Journal of Geophysical Research, Vol. 101, No. D14, 1996, pp. 19245-19250. http://dx.doi.org/10.1029/96JD03003 